\title{
El papel de los convenios urbanísticos en la planificación de nuevos espacios urbanos: el caso de Gáldar-Guía (Gran Canaria)
}

\section{The role of urban development agreements in planning new urban spaces: the case of Gáldar-Guía (Gran Canaria)}

\author{
María Mercedes Arranz Lozano*
}

\section{INTRODUCCIÓN $^{1}$}

Gáldar y Santa María de Guía son dos municipios colindantes que se localizan en la Isla de Gran Canaria, formando junto con Agaete el llamado sector noroeste de la misma. Desde la década de los años sesenta hasta la actualidad se ha producido en los mismos un importante crecimiento de la población pasando de tener 28.123 habitantes en 1960 a 64.170 en el año 2001 (cuadro 1). Este hecho se ha traducido en una expansión urbana que ha tenido lugar fundamentalmente en sus respectivos cascos fundacionales y en menor medida en la franja costera, situada en torno a $300 \mathrm{~m}$ de altitud sobre el nivel del mar. De tal manera que, en el momento presente, se puede hablar de la presencia de la conurbación de estos dos municipios generada a través del crecimiento de sus asentamientos urbanos.

\footnotetext{
*Profesora Titular. Departamento de Geografía, Universidad de La Laguna (marraz@ull.es).

${ }^{1}$ Este artículo ha sido posible gracias a la concesión del proyecto de investigación «Urbanización del territorio y política local en la Democracia Española: a vueltas con la cuestión agraria» (SEJ2007-60612), financiado por la Secretaría de Estado de Universidades e Investigación del Ministerio de Educación y Ciencia de España.
} 
En este artículo se quiere explicar un caso más de desarrollo urbanístico desaforado de los muchos de acaecidos en las Islas Canarias y que ya han sido recogidos en varias publicaciones por otros profesores de las universidades de La Laguna y de Las Palmas de Gran Canaria, como han sido los casos sobre la corrupción urbanística y el atraso en España (Martín y Jerez, 2011), los cambios en los usos del suelo en Tazacorte (isla de La Palma) (Martín Fernández, et al. 2011), o la transformación de la propiedad agraria en el sur de la isla de Gran Canaria (Hernández Luis, 2010). Dichas publicaciones han sido el resultado del proyecto de investigación en el que hemos trabajado todos nosotros y que ha quedado citado en la primera página.

El caso que ahora presento constituye un caso más de crecimiento espacial urbano que se ha realizado de acuerdo al interés particular de los agentes inmobiliarios, auspiciado por las instancias públicas, las cuales han utilizando la normativa vigente para dar legitimidad a actuaciones, cuando menos, anómalas, como ocurrió con la construcción de la urbanización de «La Guancha», en «El Agujero», sector espacial que se localiza en el ámbito costero noroeste del municipio de Gáldar (figura 2).

Las hipótesis de partida para el trabajo son las siguientes: desde los años sesenta hasta nuestros días se ha producido una gran transformación urbana en los municipios de Gáldar y Guía en el ámbito espacial localizado en las proximidades a la costa que ha originado la conurbación de ambos municipios. Algunas de las actuaciones urbanísticas se centraron en forzar el crecimiento urbano del municipio hacia sectores alejados del núcleo urbano fundacional, siguiendo el interés particular de los propietarios del suelo, convertidos asimismo en promotores inmobiliarios. Para llevar a cabo esta actuación, estos mismos promotores del suelo transformaban sus propias fincas dedicadas a la agricultura tradicional de plataneras o tomates, en fincas urbanas con la connivencia de los poderes locales y la facultad que éstos disponían sobre la planificación urbana local. Este proceso de expansión urbana se inserta en la óptica de un proceso feroz de especulación del suelo (Alcaraz Ramos, 2007), desarrollado en la mayor parte del país y sobre todo en Canarias, dónde además se liga a la trascendencia que aquí tiene la función turística, intensificada aún más desde los años ochenta.

\section{LA ENREDADA MARAÑA DE LA NORMATIVA URBANÍSTICA EN CANARIAS}

La configuración del Estado de las Autonomías trajo consigo el traspaso de competencias en materia de urbanismo, ordenación del territorio, medio am- 
FIGURA 1

MAPA DE LA ISLA DE GRAN CANARIA

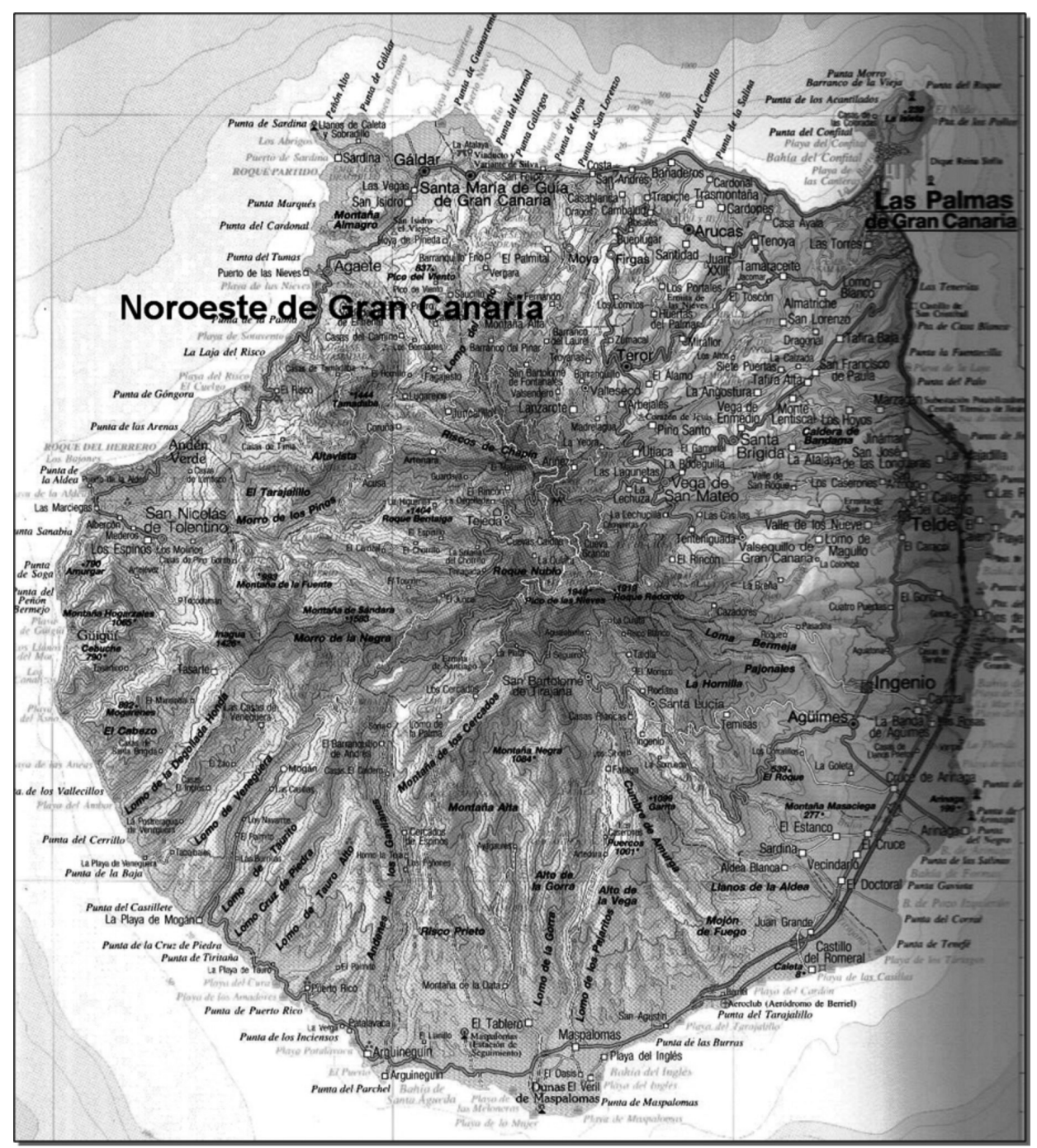

Fuente: Enciclopedia Larousse, Atlas de España /2, Escala 1:250.000.

Estudios Geográficos, Vol. LXXIV, 274, pp. 7-44, enero-junio 2013 ISSN: 0014-1496, eISSN: 1988-8546, doi: 10.3989/estgeogr.201301 
biente, turismo, etc.., originando así la existencia de un cuerpo legislativo de alcance nacional y otro de Comunidad Autónoma, el cual, debe someterse al anterior por ser de ámbito administrativo inferior. A todo ello se une, en Canarias, las transferencias de funciones de la administración pública de la Comunidad Autónoma a los Cabildos Insulares, en materia de promoción y política del turismo insular, así como los Planes de Ordenación Insular cuya competencia corresponde a los Cabildos en materia de ordenación territorial a escala supra municipal.

Por lo que se refiere a la legislación de alcance estatal se cuenta con la primera Ley sobre Régimen del Suelo y Ordenación Urbana, aprobada en mayo de 1956 que expresaba la facultad de realizar Planes Generales y Planes Parciales en la ordenación urbana de los municipios. Desde entonces han ido apareciendo sucesivas leyes, referidas al régimen del suelo a lo largo de las décadas de los años setenta, ochenta y noventa hasta llegar a la actual Ley del Suelo de 28 de mayo de 2007 y el Real Decreto Legislativo de 20 de junio de 2008 , por el que se aprueba el texto refundido de la anterior Ley. De todas las existentes en las décadas señalada sea la Ley 6/1998 de 13 de abril la más significativa ya que ha sido la que ha facilitado toda la operación de urbanización de los municipios españoles en el periodo del boom inmobiliario en España desde 1998 a 2008.

Por lo que se refiere al cuerpo legislativo de Canarias desde que se aprobó el Real Decreto 2843/1979 de 7 de diciembre, por el que se transfirieron a esta Comunidad Autónoma competencias en materia de Administración Local, y hasta el momento actual, se han aprobado un gran número de normas jurídicas orientadas no sólo al urbanismo y la ordenación del territorio sino también a la evaluación medio ambiental, su impacto en el territorio, turismo, etc. De todas las referidas a la Ordenación del Territorio la más importante ha sido el Decreto Legislativo $1 / 2000$, de 8 de mayo por el que se aprueba el texto refundido de las Leyes de Ordenación del Territorio y de Espacios Naturales de Canarias (TRLOTENC) que refunde las disposiciones de: La Ley 9/1999, de 13 de mayo, de Ordenación del Territorio de Canarias; Ley 12/1994, de 19 de diciembre, de Espacios Naturales de Canarias y Ley 13/1994 de 22 de diciembre de Modificación del Anexo de la Ley anterior. Este Decreto ha supuesto desde su aprobación, uno de los principales instrumentos de esta Comunidad Autónoma sobre Ordenación del Territorio y en la cual debe de integrarse lo redactado en los nuevos Planes Generales de Ordenación Urbana aprobados en los municipios de las islas (Anexo/cuadro II).

Después de ese Decreto Legislativo han sido publicadas diversas normas jurídicas como han sido: Ley 6/2001, de 23 de julio, de medidas urgentes en 
materia de Ordenación del Territorio y del Turismo en Canarias (Primera moratoria); Decreto 127/2001, de 5 de julio, por el que se regulan las Directrices de Ordenación; Decreto176/2001, de 6 de septiembre, por el que se acuerda el inicio de la elaboración de las Directrices de Ordenación General y de Turismo; Ley 6/2002, de 12 de junio, sobre Medidas de Ordenación Territorial, de la actividad turística en las islas de El Hierro, La Gomera, La Palma; Ley 19/2003, de 14 de abril, por la que se aprueban las Directrices de Ordenación General y de Ordenación de Turismo de Canarias, también conocida como «La Moratoria» (segunda moratoria) que recoge y complementa los principios generales de sostenibilidad formulados a nivel internacional y estatal; el Decreto 55/2006, de 9 de mayo, por el que se aprueba el Reglamento de Procedimientos de los Instrumentos de Ordenación del Sistema de Planeamiento de Canarias; Ley 6/2009, de 6 de mayo, de medidas urgentes en materia de Ordenación Territorial para la Dinamización Sectorial y la Ordenación del Turismo (Tercera y última moratoria, hasta la actualidad) (Anexo/cuadro II).

Algunos especialistas piensan que toda esta proliferación de normas jurídicas en materia de urbanismo y ordenación territorial no es eficaz para un desarrollo sostenible y «...que derivan del sistema impuesto en España en 1956, los cuales constituyen un lastre al ser obsoleto, por lo que urge su adaptación y modernización. Además este sistema produce normas en exceso que resultan contradictorias entre sí» ${ }^{2}$. Otras personas como es el caso del magistrado del Tribunal Superior de Justicia de Canarias, Javier Gómez-Acedo, opinan que ha sido las causantes de la existencia de casos de corrupción urbanística en esta Comunidad Autónoma al afirmar «que el sistema jurídico de ordenación urbanística en Canarias posibilita y fomenta la existencia de ilícitos urbanísticos, ya que la Comunidad está situada como la segunda donde más casos de corrupción urbanística se producen en España» ${ }^{3}$.

El CONOCIMIENTO DEL MEDIO GEOGRÁFICO DE GÁldAR-Guía COMO ELEMENTO DE ANÁLISIS PARA EL DESARROLLO ESPACIAL DE SU CONURBACIÓN URBANA

Gáldar y Santa María de Guía son dos municipios que, en el año 1960, contaban con una población de 16.160 y 11.963 habitantes, respectivamente (fi-

\footnotetext{
${ }^{2}$ Declaraciones realizadas por Luciano Parejo, catedrático de Derecho Administrativo de las universidades de La Laguna, Alcalá de Henares y Carlos III de Madrid, al diario EL DÍA, 15 de octubre de 2010, p. 18.

${ }^{3}$ Declaraciones manifestadas por este magistrado publicadas el 14 de abril de 2011 en el diario LA PROVINCIA/DLP (Diario de Las Palmas), p. 21.
} 
gura 1 y 2 , y cuadro 1). De acuerdo a la definición del INE por el tamaño de su población — superior a 10.000 habitantes—, ambos municipios debían de ser considerados como núcleos urbanos; sin embargo, a pesar de su tamaño, funcionalmente todavía no podían ser considerados como tales ya que basaban su economía en las actividades agrícolas, principalmente en la explotación del cultivo del plátano y del tomate. Por esta razón desarrollaban un crecimiento espacial muy lento, centrado básicamente en sus respectivos núcleos fundacionales (figura 3 ).

En la década de los años ochenta del siglo xx ambos municipios pasan a tener una economía basada en los sectores de la construcción (147\%) y de los servicios (42'9\%) y por tanto pueden considerarse ya como núcleos urbanos. Algunos propietarios de grandes extensiones de plataneras, transformaron el suelo agrícola de sus explotaciones en urbano, convirtiéndose así en grandes propietarios de suelo urbano y en, algunas ocasiones, en directores de sus propias empresas inmobiliarias. Así se erigieron como los verdaderos productores del suelo urbano y los responsables del crecimiento espacial que se desarrolló, sobre todo en la franja costera, porque era en este ámbito — que ocupa aproximadamente un $60 \%$ de la superficie municipal-, donde el interés turístico ofrecía importantes expectativas ${ }^{4}$.

Para entender este desarrollo urbano no se puede obviar el papel que ha jugado la distribución de la población en el noroeste de la isla de Gran Canaria, con anterioridad a los años sesenta del siglo xx. De acuerdo a lo señalado por el profesor Martín Ruiz, es «... en el periodo de 1920-1960 cuando se produce un auge demográfico de tal magnitud que en sólo cuarenta años la población en el NW de la isla se multiplica por dos pasando de tener 17.358 habitantes en 1930 a 33.202 en 1960» (Martín Ruiz, 1989, p. 76), siendo Gáldar el que presenta el crecimiento intercensal más alto de los tres y casi duplicando su población al igual que los otros dos municipios (cuadro 1).

Este crecimiento poblacional tan importante se debió al boom de la explotación intensiva de los cultivos de exportación, plataneras y tomateras, a finales de la Primera Guerra Mundial que ocasionó un crecimientos demográfico generalizable en todo el archipiélago y más concretamente en las franjas costeras de los municipios donde el clima y los aprovechamientos de agua obte-

\footnotetext{
${ }^{4}$ Normas Subsidiarias 1985, redactadas por los arquitectos J. F. Henríquez Sánchez y A. Cervera Llamazares para la empresa Gestión Urbanística de las Palmas S. A., en 1982. Índice General, capítulo 2 Encuadre Municipal, p. 1.
} 
FIGURA 2

\section{PLANO DE SITUACIÓN DE GÁLDAR - GUÍA}

\section{GRAN CANARIA}

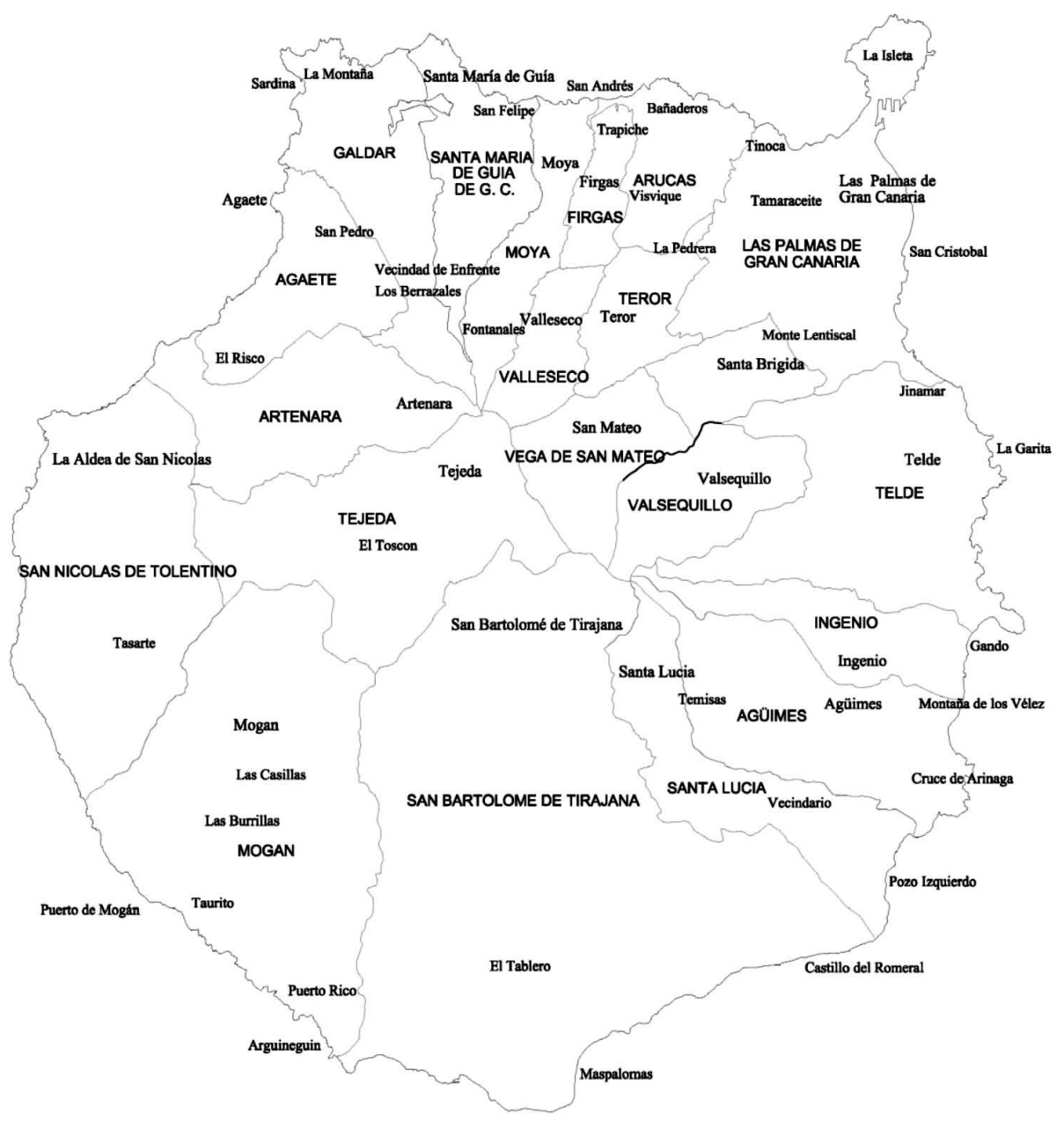

Fuente: Ayuntamiento de Gáldar. PPT-14 Escala 1:100.000. 
nidos de la existencia de barrancos y la explotación de acuíferos originaban las condiciones excelentes para estos cultivos ${ }^{5}$. Este hecho dio lugar a que dicho sector espacial se convirtiera en centro de recepción de trabajadores, sobre todo de aquellos que residían por encima de los $300 \mathrm{~m}$ de altitud - medianías y cumbres- de Gáldar, Guía y en otros municipios, los cuales llegaron a trabajar en la explotación de aquellos cultivos y en las actividades ligadas a ellos: almacenes de empaquetados que requieren mucha mano de obra asalariada ${ }^{6}$. A modo de ejemplo, el municipio de Gáldar creció, en el sector de la costa a un ritmo de 2'4\% desde 1920 a 1960, en función de la expansión de su centro fundacional y también del desarrollo urbano de otros barrios

\section{CuAdro 1}

EVOLUCIÓN DE LA POBLACIÓN EN EL NOROESTE DE GRAN CANARIA 1900-2011

\begin{tabular}{|c|c|c|c|c|c|c|c|c|}
\hline \multirow[t]{2}{*}{ Años } & \multicolumn{4}{|c|}{ Población de Hecho } & \multicolumn{4}{|c|}{$\begin{array}{c}\text { Tasa media anual de Crecimiento } \\
\text { de la población }\end{array}$} \\
\hline & Agaete & Gáldar & Guía & Total NW & Agaete & Gáldar & Guía & Total NW \\
\hline 1900 & 2.835 & 5.278 & 5.247 & 13.360 & 0,37 & 2,59 & 0,47 & 1,26 \\
\hline 1910 & 3.124 & 6.460 & 6.422 & 16.006 & 0,98 & 2,04 & 2,04 & 1,82 \\
\hline 1920 & 3.126 & 7.349 & 6.883 & 17.358 & 0,01 & 1,30 & 0,70 & 0,81 \\
\hline 1930 & 4.208 & 9.951 & 8.449 & 22.608 & 3,02 & 3,08 & 2,07 & 2,68 \\
\hline 1940 & 4.700 & 11.816 & 10.829 & 27.345 & 1,11 & 1,73 & 2,51 & 1,92 \\
\hline 1950 & 4.366 & 13.704 & 11.851 & 29.921 & $-0,73$ & 1,49 & 0,91 & 0,90 \\
\hline 1960 & 5.079 & 16.160 & 11.963 & 33.202 & 1,52 & 1,66 & 0,09 & 1,05 \\
\hline 1970 & 4.414 & 16.995 & 11.435 & 32.844 & $-1,39$ & 0,51 & $-0,45$ & $-0,11$ \\
\hline 1981 & 4.427 & 18.410 & 12.040 & 34.877 & 0,03 & 0,80 & 0,52 & 0,60 \\
\hline 1991 & 4.777 & 20.370 & 12.120 & 37.267 & 0,76 & 1,02 & 0,07 & 0,67 \\
\hline 2001 & 5.202 & 22.154 & 13.893 & 41.249 & 0,86 & 0,84 & 1,37 & 1,02 \\
\hline $\begin{array}{l}\text { Proyección } \\
2011(*)\end{array}$ & 5.665 & 24.094 & 15.925 & $45.656\left(^{*}\right)$ & - & - & - & - \\
\hline
\end{tabular}

Nota: $\left(^{*}\right)$ En el momento actual asistimos a la práctica elaboración del último Censo de Población y Viviendas en España, pero todavía no se han publicado los resultados definitivos.

Fuente: INE y Martín Ruiz, J. F. (1989).

\footnotetext{
${ }^{5}$ Martín Ruiz, 1989, p. 79.

${ }^{6}$ Martín Ruiz, 1989, p. 77.
} 
como fue el de «La Montaña» y en particular el de «San Isidro», que pasó de tener 453 habitantes en 1920 a 3.726 en 19607. Este intenso crecimiento demográfico de la población en la zona de la costa, ya no abandonará a estos dos municipios en las décadas posteriores y será el elemento decisivo para que la planificación centre la expansión urbana, de estos municipios, fundamentalmente en este sector. No olvidemos que en 1960 un 63,7\% de población activa en el noroeste de la isla se dedicaba a la agricultura, un 13'9\% se dedicaba a las actividades industriales y un 21 ' $8 \%$ se dedicaba al sector servicios - con un muy bajo nivel de instrucción o analfabetismo-, situación que cambia en 1981 , siendo estos porcentajes respectivamente de $31 \%$ en el sector primario 26 ' $1 \%$ en el secundario -incluyendo energía, agua y construcción- y 42 '9\% en el terciario ${ }^{8}$.

LA NORMATIVA URBANÍSTICA COMO FIGURA DETERMINANTE EN EL CRECIMIENTO ESPACIAL DE GÁldAR-GUÍA

En estos dos municipios se produjo un proceso de expansión urbana muy importante, en el periodo 1990-2007, que se insertó en la óptica de un modelo de especulación del suelo basado en el proceso de potenciación del sector de la construcción - promoción inmobiliaria con función residencial o turística- respaldado por el apoyo del sector financiero y bursátil, en la mayor parte del país y sobre todo en las áreas donde se ha desplegado también la función turística, como es el caso de las Islas Canarias, muy en particular en Gran Canaria y Tenerife, coincidiendo con la fase expansiva del ciclo económico para la vivienda y el extraordinario boom de la construcción en nuestro país, desde 1995 a 2007 (Jiménez Sánchez, 2008). Dicho proceso de expansión urbana vendrá determinado, asimismo, por la planificación del suelo que se realizó durante ese periodo (Lobo Rodrigo, A., 2010).

\section{La planificación urbana de Gáldar y Guía hasta 1985}

Hasta los inicios de la década de la década de los ochenta, fueron las Normas Subsidiarias y complementarias de planeamiento de ámbito provincial, con vigencia desde el año 1973, las que regían el crecimiento urbano de Gál-

\footnotetext{
${ }^{7}$ Martín Ruiz, 1989, p. 79.

${ }^{8}$ Martín Ruiz, 1989, pp. 87 y 126.
} 
dar, Guía y el de la mayoría de los municipios de la provincia de Las Palmas. Es a partir de aquella década cuando se empezaron a redactar Normas Subsidiarias de Ordenación del Planeamiento Municipal en todos los municipios de esta provincia, a excepción de Betancuria y Teror. En alguno de ellos, la redacción de las mismas se encontraba ya en curso de elaboración muy avanzado, como La Oliva —en fase de tramitación en 1982- y Tinaje —en período de Aprobación del Avance en ese mismo año-. Sólo en unos cuantos municipios se empezaron a redactar, por primera vez, Planes Generales de Ordenación Urbana, como fue el caso de Las Palmas de Gran Canaria — redactando la actualización de su Plan General en 1982-, Arrecife — tramitando la revisión y actualización del suyo, en ese mismo año—, Pájara —que ya lo había aprobado en 1978- y Yaiza — sometiendo su Plan a revisión urgente-. Con anterioridad a la aprobación de las Normas Subsidiarias señaladas en los municipios de Gran Canaria era frecuente la construcción de viviendas espontáneas, lo que dio lugar a la aparición de importantes sectores de crecimiento urbano ilegal, sobre todo en las proximidades a la costa (Martín Fernández, 2011). Incluso una vez aprobadas aquellas, siguió persistiendo dicho fenómeno en gran parte de los municipios de la isla y, como no, también en Gáldar y Guía (Rodríguez Martín, 1978) (figura 2).

Es en 1982 cuando comienzan a redactarse las Normas Subsidiarias de Ordenación del Planeamiento Municipal, que tanto en Guía como en Gáldar, constituirán el primer elemento de ordenación territorial, con carácter muni$\mathrm{cipal}^{9}$. Ambas fueron redactadas conforme a lo dispuesto en el artículo 71 del texto refundido de La Ley sobre Régimen del Suelo y Ordenación urbana de 1976, en su artículo 93, y el Reglamento de Planeamiento (Real Decreto 2159/1978, de 23 de junio) que desarrolla dicha Ley ${ }^{10}$.

En el municipio de Guía, esas primeras Normas Subsidiarias de Ordenación del Planeamiento Municipal han estado rigiendo el crecimiento espacial urbano del municipio hasta el 28 de julio de 2005, fecha en la que se aprobó definitivamente el Plan General de Ordenación Urbana de Guía. Sin embargo en Gáldar, como veremos en las páginas siguientes, después de aprobadas las primeras Normas Subsidiarias de Ordenación del Planeamiento Municipal en 1985 y hasta la aparición de su actual Plan General de Ordenación Urbana, se

${ }^{9}$ Aprobadas definitivamente por la Comisión Provincial de Urbanismo en sesión plenaria el 21 de julio de 1983 en Guía y el 14 de noviembre de 1985 en Gáldar.

${ }^{10}$ Documento Definitivo, de las Normas Subsidiarias respectivas de los municipios de Guía y Gáldar: Volumen 1. «Información urbanística». 


\section{FIGURA 3}

\section{LOS ASENTAMIENTOS EN EL MUNICIPIO DE GÁLDAR}

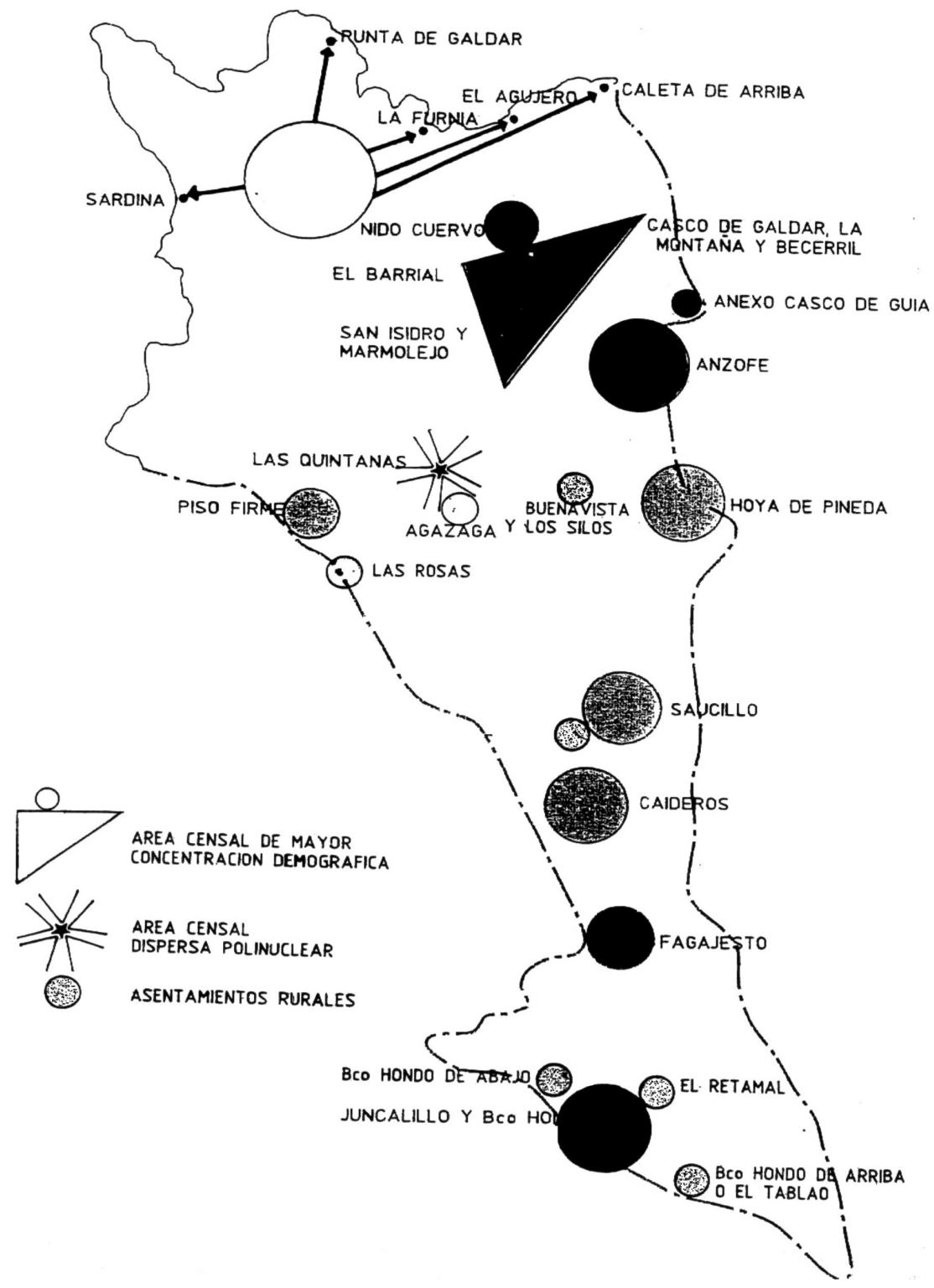

Fuente: Revisión de las Normas Subsidiarias 1996, Ayuntamiento de Gáldar. 
sancionaron otras Normas Subsidiarias en 1997 (ver anexo cuadro 3). Este hecho supone un testimonio de la existencia de una mayor ambición por la edificación del suelo en el municipio de Gáldar ya desde la década de los noventa del siglo pasado (Serrano Martínez, 2004).

Como se puede apreciar en la figura 3 la distribución espacial de la población en Gáldar se ha constituido, desde sus orígenes, en distintos asentamientos, urbanos y rurales (Martín Ruiz, 2005). De todos ellos el más grande en tamaño es el casco fundacional, que lógicamente ha sido el que ha concentrado mayor densidad demográfica y ha experimentado el mayor desarrollo de actividades urbanas. Junto a él se han ido desarrollando hacia el oeste Nido Cuervo, Barrial, San Isidro y Marmolejo y hacia el este, el caso urbano de Gáldar se ha ido uniendo paulatinamente con el del municipio colindante de Guía a través del anexo del casco histórico de Guía y del asentamiento de Anzofé, de tal manera que se puede afirmar que en el momento actual existe una conurbación entre los dos núcleos urbanos a través de este sector espacial.

En 1985, se aprobaron en Gáldar las primeras Normas Subsidiarias municipales para la Ordenación Urbana, si bien es cierto que ya existían con anterioridad Normas Provinciales para el desarrollo urbano del municipio ${ }^{11}$ (ver anexo cuadro 3). Uno de los hechos que más llama la atención en las aprobadas en el año ochenta y cinco es la inclusión en ellas de dos planes parciales. El primero era el denominado Plan Parcial Playa Canarias ${ }^{12}$, que fue aprobado con fecha de 27 de marzo de 1969. De acuerdo a lo redactado se situaba en el sector de Sardina del Norte, en un entorno costero, donde se localizaba un enclave de viviendas de autoconstrucción (figura 2). Se le determinaba un uso del suelo de carácter turístico, abarcando una superficie de $724.363 \mathrm{~m}^{2}$; en 1982 se encontraba ejecutado en su práctica totalidad.

El segundo de los planes parciales, fue aprobado el 5 de febrero de 1971. Se localizaba en el barrio de San Sebastián, en las proximidades al casco fundacional de Gáldar y se le adjudicaba un uso de suelo de tipo residencial a desarrollar en $20.131 \mathrm{~m}^{2}$ de superficie ${ }^{13}$. Gracias a este Plan Parcial se urbanizó

${ }^{11}$ Normas Subsidiarias de Ordenación del Planeamiento Municipal, 1985, redactadas por los arquitectos J. F. Henríquez Sánchez y A. Cervera Llamazares para la empresa Gestión urbanística de las Palmas, S.A., en 1982, «Información urbanística», Volumen 1, «Encuadre Regional», p. 4 y Volumen 2, capítulo III, Planeamiento Existente, p. 1.

12 El Plan Parcial, de acuerdo a lo establecido en la Ley del suelo de 1956, suponía la tarea exigida para el desarrollo de un Plan General y la actuación por polígonos a construir (Arranz Lozano, M., 1990, p. 146). 
una gran parte de ese barrio, quedando sin construir una pequeña parte alejada de la carretera general que entrelazaba Gáldar con el resto de la isla, la cual se construirá años más tarde a partir de la firma de un Convenio Urbanístico.

La aprobación de estos dos planes parciales, nos pone en la pista de la manifiesta avidez especulativa por el suelo urbano que empieza a despertarse con anterioridad a los años ochenta en el municipio de Gáldar y que, incluso, queda de nuevo puesta de manifiesto en la redacción de las propias Normas Subsidiarias del ochenta y cinco: «La carencia de Planes Generales y consecuentemente la falta de previsiones ha propiciado la gran profusión del planeamiento con fines exclusivamente especulativos, como consecuencia de los cuales nos encontramos con un impresionante exceso de suelo calificado (incluso en municipios regresivos), del que únicamente una mínima parte está preparado para edificar» ${ }^{14}$. A este hecho se une la importancia que está comenzando a tener, en esos momentos, la compra y la venta de terrenos para el posterior desarrollo urbano en el municipio que queda de manifiesto cuando se indica: «La dispersión de barrios (en Gáldar) a pesar de no ser muy acusada es importante por ser un fenómeno que ha adquirido mucho auge en los últimos tiempos, provocado por el alto valor del suelo en los cascos urbanos ya consolidados» ${ }^{15}$.

Otro hecho que nos habla de la preocupación que hay dentro del Ayuntamiento por la urbanización del suelo en el municipio es la aparición, en abril de 1987, de nuevos planos a escala 1:2.000 realizados por la Oficina Técnica del Ayuntamiento de Gáldar a los que denominan «Modificación de las Normas Subsidiarias de Planeamiento del Municipio de Gáldar: Usos pormenorizados en suelo urbano y suelo apto para urbanizar» los cuales varían lo que ya estaba cartografiado previamente en los planos insertos en las Normas Subsidiarias — aprobadas dos años antes - en los siguientes barrios: Plano 1, Sector S. U. - Suelo Urbano- Sardina (abril, 1987); Plano 2, Sector S. U. Barrial Nido Cuervo; Plano 3, Sector S.U. San Isidro - Marmolejos; Plano 4, Sector S. U. Anejo al Casco de Guía y Plano 5: Sector S. U. Gáldar - La Montaña de Be-

${ }^{13}$ Normas Subsidiarias de Ordenación del Planeamiento Municipal, 1985 (ver bibliografía), redactadas por los arquitectos J. F. Henríquez Sánchez y A. Cervera Llamazares para la empresa Gestión urbanística de las Palmas, S.A., en 1982, «Información urbanística», Volumen 1, «Encuadre Regional», p. 4 y Volumen 2, capítulo III, Planeamiento Existente, p. 2.

${ }^{14}$ Ibíd.: Documento Definitivo, 2. Normativa, capítulo I: Normas Generales, p. 1 y 2.

15 Normas Subsidiarias de Ordenación del Planeamiento Municipal (ver bibliografía Volumen 1, capítulo 2 Encuadre Municipal, p. 8. 
cerril. Cada uno de estos cuatro últimos planos lleva inscrita la siguiente leyenda «(abril, 1987). El cual queda anulado y sustituido por el modificado acorde con la CUMAC de 29/01/1988. Definitivo de septiembre de 1988, acorde con el de 29/01/1988 ${ }^{16}$. Ello quiere decir que la citada Oficina Técnica de Gáldar había realizado unos nuevos planos haciendo modificaciones en los anteriormente aprobados y los había enviado a la Consejería de Urbanismo y Medioambiente de Canarias (CUMAC) para su aprobación, pero ésta los había rechazado y mandado rehacer.

¿Pero por qué estas prisas para modificar planos de los barrios a los dos años de aprobarse la Normas Subsidiarias? Es evidente que se intenta recalificar el suelo rural en urbano, y con ello adquirir mayor precio en el proceso de compra-venta.

\section{Los Convenios Urbanísticos como elemento organizador del crecimiento espacial en Gáldar}

En el año 1993, seis años más tarde de las modificaciones cartográficas realizadas en la Oficina Técnica de Planeamiento, se inicia la redacción de un nuevo documento de ordenación urbana denominado «Revisión de las Normas Subsidiarias del municipio», que en 1997 vendrá a sustituir a las primeras Normas aprobadas en $1985^{17}$. Una vez aprobado dicho documento de manera inicial, en mayo de 1994, y sin llegar a esperar su aprobación definitiva, el Alcalde, D. Demetrio Suárez Díaz en representación del Ayuntamiento de Gáldar y determinadas personas físicas, irán firmando diferentes «Convenios Urbanísticos» en uso de las facultades que le confiere La Ley 7/1985, de 2 de abril, Reguladora de las Bases del Régimen Local (LBRL) (Suay Rincón y Domínguez Vila, 2010).

La pregunta que surge inmediatamente es la siguiente: ¿por qué usar la figura del Convenio Urbanístico para producir espacio urbano? De acuerdo que esa era una figura legal que se podía utilizar, pero ¿por qué no aprobar diferentes Planes Parciales como había sucedido en los sectores de Sardina Norte y el barrio de San Sebastián? La respuesta se materializaba en que un Convenio Urbanístico lo firma siempre el Alcalde, como representante del Ayuntamiento y un particular — persona física o jurídica - y no tiene la obligación

\footnotetext{
16 Planos revisados en Oficina Técnica del Ayuntamiento de Gáldar.

17 Redactadas por la arquitecta Cándida R. Benítez Suárez, fueron aprobadas inicialmente en mayo de 1994, de forma definitiva parcial el 9 de mayo de 1996 y definitivamente el 28 de enero de 1997.
} 
de ser aprobado por el Pleno del Gobierno local, lo cual dificulta la labor de control de la oposición política. Este hecho no puede considerarse como un acto de corrupción, ya que se realiza con respeto a las normas vigentes, pero sí demuestra la especulación y la alianza entre el poder local —representado por el Alcalde- y los propietarios del suelo y las empresas inmobiliarias ${ }^{18}$.

Entre todos los convenios urbanísticos que se firmaron cabe destacar los siguientes: en primer lugar el «Convenio Urbanístico suscrito por el Excmo. Ayuntamiento de Gáldar y los propietarios de los solares previstos como manzanas edificables denominadas M-1, M-2 y M-3 en la Unidad de Ejecución (U. E. 4 / Urbanización San Sebastián)» ${ }^{19}$. Se trata de la urbanización de estas tres últimas manzanas que faltaban por edificar en la urbanización residencial San Sebastián $\left(20.131 \mathrm{~m}^{2}\right.$ ) configurada ya a partir de un Plan Parcial aprobado el 5 de febrero de 1971. En las Normas Subsidiarias de 1985, se permite la edificación en estas manzanas de residencias con una serie de restricciones en su construcción, pero con la firma de este nuevo Convenio Urbanístico se consigue cambiar estas restricciones y obtener unas condiciones más ventajosas para los propietarios.

En efecto, se permite a los propietarios, entre otras cosas, realizar « 75 viviendas/Ha.; 90 viviendas en bloques y hasta 35 unifamiliares, conforme a la ordenanza que más adelante se definirá, dejar $25 \mathrm{~m}^{2} / \mathrm{Ud}$., como mínimo de zona libre de uso público por vivienda». A cambio el Ayuntamiento exige para él mismo, «20 plazas de aparcamiento ubicadas en el subsuelo del espacio libre; el $15 \%$ de las plazas de aparcamiento proyectadas pudieran construirse con la aprobación del Ayuntamiento en el subsuelo del espacio libre de uso público y 28 millones de pesetas Pagaderos en la forma que más adelante se especificará». En este mismo Convenio Urbanístico se especifica que «Una vez aprobada definitivamente la Revisión de las Normas Subsidiarias, las cuáles incluyan íntegramente lo dispuesto en el presente Convenio Urbanístico, los propietarios firmantes dispondrán de un plazo de seis meses para presentar ante el Ayuntamiento el proyecto de urbanización...» ${ }^{20}$.

${ }^{18}$ La corrupción, de existir, podría producirse siempre y cuando se obtuviera la compra de las voluntades de los representantes del poder local.

${ }^{19}$ Documento Privado localizado en el Excmo. Ayuntamiento de Gáldar, no 7691 con Registro de entrada 23 de julio de 1994. En este Convenio Urbanístico caso nos damos cuenta de que los propietarios de suelo que firman el mismo lo forman dos grupos de tres hermanos, otros dos grupos de dos hermanos y dos personas físicas más que no tienen relación de parentesco. (Convenio Urbanístico firmado el 23 de julio de 1994, páginas, I y II).

${ }^{20}$ Ibíd., página $\mathrm{V}$. 
El segundo Convenio Urbanístico que merece la pena destacar fue firmado con fecha 3 de mayo de 1994, entre el Alcalde y la empresa Herdosán, S.A. para anexar la parcela al S.A.U. - 2 (R) S-1, —Suelo Apto para Urbanizar, Residencial, Sector $1-$ a través del cual la empresa propietaria de una parcela calificada como rural, próxima a la mencionada, la anexaba a la misma recalificándola como suelo apto para urbanizar a cambio de otorgar al Excmo. Ayuntamiento veinticinco millones de pesetas ${ }^{21}$.

Pero el Convenio Urbanístico más significativos de todos los realizados en la segunda mitad de los noventa fue el que se firmó el 21 de julio entre el Alcalde D. Demetrio Suárez y D. Félix Santiago Melián, para «el desarrollo y gestión del suelo en el Agujero». Con el nombre «El Agujero» se conoce en Gáldar un pequeño barrio formado por casas de autoconstrucción situado al norte del municipio, muy alejado del casco fundacional del mismo y muy frecuentado por los vecinos como lugar de baño y de diversión por la playa que allí existe (figura 3). Este sector espacial ya quedaba señalado en las Normas Subsidiarias de 1985, como «Un núcleo muy pequeño y sin apenas crecimiento» determinándolo como «sector de uso Residencial Turístico que tendrá como finalidad primordial dar la posibilidad de desarrollo turístico del municipio» ${ }^{22}$, para lo cual «está prevista un concurso de ideas sobre la zona, con el fin de permitir a la iniciativa privada el correspondiente Plan Parcial acorde con la idea premiada» ${ }^{23}$, respetándose en todo momento los dos yacimientos arqueológicos que se encuentran en sus alrededores denominados «El Agujero»y «La Guancha».

El desarrollo turístico señalado para este sector del «Agujero» nunca se llevó a su término; sin embargo, lo que sí se realizó fue la firma del Convenio Urbanístico señalado, para el desarrollo de una urbanización residencial en sus proximidades. En dicho convenio D. Félix Santiago Melián aportó cuatro parcelas rústicas dedicadas al cultivo de plataneras y dos fincas urbanas de propiedad. Todas ellas habían pertenecido, con anterioridad a David J. Leacock — conocido por los vecinos del municipio como Mr. Leacock-, un empresario inglés, cuyo padre había llegado a Gran Canaria a comienzos del siglo xx

${ }^{21}$ Convenio Urbanístico entre el Ayuntamiento y D. José Abraham Domínguez Santana en calidad de Consejero Delegado de una Sociedad mercantil, páginas I y II

22 Ibíd., «Documento Definitivo», Anexo 2 al capítulo 4, Suelo Apto para Urbanizar. Memoria justificativa de los diferentes sectores, pág. A.2.4.1.

${ }^{23}$ Ibíd., «Documento Definitivo», Anexo 3 al capítulo 4, Prioridades en el Desarrollo y Gestión de los distintos sectores de suelo apto para urbanizar, pág. A.3.4.1. 
para establecer y dinamizar el comercio de los plátanos con Inglaterra. Negocio que él heredó y amplió comprando un gran número de fincas agrícolas para dedicar al cultivo del plátano y del tomate. A su muerte dejó en su testamento como herederos de su empresa y de sus propiedades a once de sus trabajadores, los cuales se constituyeron en la «Sociedad Cooperativa Herederos de Mr. Leacok» para la explotación de aquélla. Dicha empresa, entró en quiebra en el año 1992, y tanto ésta como las fincas propiedad de la Sociedad fueron vendidas a D. Félix Santiago Melián, que pasó a ser su nuevo propietario. (Torrent Navarro, Amador y Suarez Bosa, 1995).

La firma de este Convenio Urbanístico servirá para que todo este suelo pase a calificarse como suelo apto para urbanizar, unidad familiar (SAU)-1 (UF), en el nuevo documento de planificación urbana del municipio «Revisión de las Normas Subsidiarias» que se estaba redactando en ese año y que será aprobado definitivamente en el año 1997. A cambio el propietario de este suelo tendrá que pagar al Ayuntamiento de Gáldar 15 millones de pesetas que «que será abonado a la aprobación definitiva del Plan Parcial del suelo comprendido en el SAU» ${ }^{24}$, que le obligaban a realizar en el plazo de un año después de la aprobación de las nuevas Normas Subsidiarias y que no llegó a cumplir. En dicho Convenio se estipulaban además las siguientes condiciones: construcción de viviendas unifamiliares aisladas $\left(37.900 \mathrm{~m}^{2}\right)$; viviendas unifamiliares pareadas / hilera $\left(15.600 \mathrm{~m}^{2}\right)$; comercial privado $\left(1.600 \mathrm{~m}^{2}\right)$; zona verde / E. libre $\left(15.440 \mathrm{~m}^{2}\right)$; escolar / cultural $\left(5.000 \mathrm{~m}^{2}\right)$; deportivo $\left(9.000 \mathrm{~m}^{2}\right)$; vías de $20 \mathrm{~m}$ de ancho $\left(15.000 \mathrm{~m}^{2}\right)$; y vías de $9 \mathrm{~m}$ de ancho $\left(25.610 \mathrm{~m}^{2}\right)$ obteniéndose una superficie total edificada de $124.750 \mathrm{~m}^{2}$, de los cuales $92.125 \mathrm{~m}^{2}$ (73'85\%) eran propiedad de D. Félix Santiago Melián y $32.625 \mathrm{~m}^{2}(26,15 \%)$ de otros propietarios, a los que posteriormente este señor se los compraría. También en el plano E 1:300, que presenta en el Convenio Urbanístico, el Yacimiento arqueológico de «La Guancha» aparece calificado como zona verde / E. libre.

Todo lo firmado en este Convenio Urbanístico quedará íntegramente recogido en La «Revisión de las Normas Subsidiarias del municipio de Gáldar. Texto refundido» ${ }^{25}$ refiriéndose al mismo como «un sector que ha surgido como iniciativa particular instrumentada vía Convenio Urbanístico y la im-

${ }^{24}$ Convenio Urbanístico para el desarrollo y Gestión del Suelo en «El Agujero», en el Término Municipal de Gáldar. Firmado en Gáldar, 21 de julio de 1994.

25 Aprobado definitivamente en mayo de 1997 y publicado en el Boletín Oficial de la Provincia de las Palmas, el 11 de julio de 1997. 
FIGURA 4

«EL AGUJERO» ORDENACIÓN S.A.U - 1 (UF) DE GÁLDAR

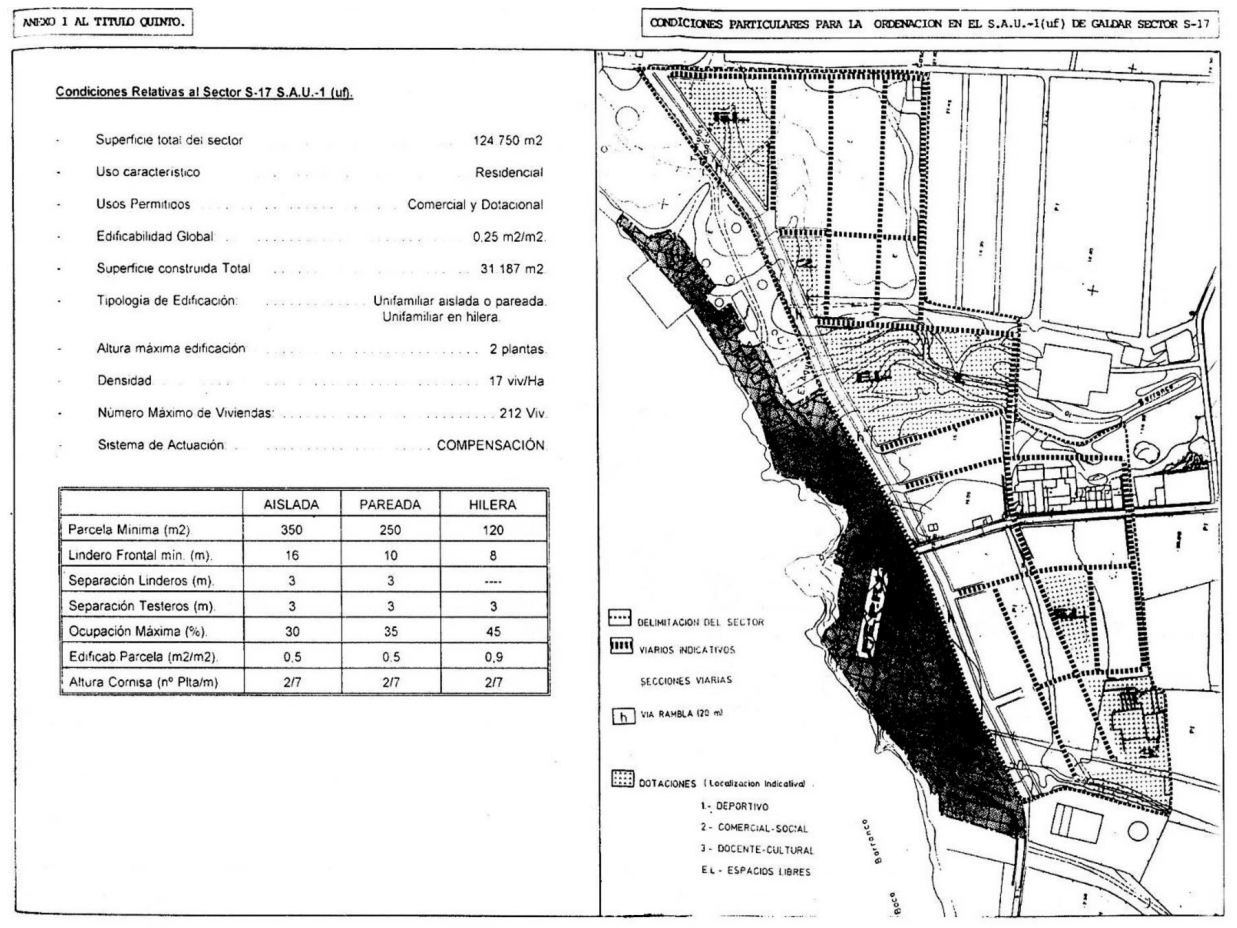

Fuente: «Revisión de las Normas Subsidiarias de Planeamiento del Municipio de Gáldar». Boletín Oficial de la Provincia de las Palmas, 11 de julio de 1997.

plantación de la vivienda unifamiliar aislada o adosada como tipología predominante en ellos» ${ }^{26}$, lo que confirma una vez más la legitimidad de estos Convenios, si bien su finalidad no responde al interés general de la panificación municipal sino al desarrollo de un interés muy particular (figura 4).

Con fecha de 13 de octubre de 2000 se aprobó el «Proyecto de Compensación Sector 17, Suelo Apto para urbanizar de El Agujero», presentado por la Junta de Compensación Entidad Urbanística de Compensación del Plan Parcial Sector 17 El Agujero, Urbanización Costa Agujero ${ }^{27}$. Los miembros inte-

${ }^{26}$ Revisión de las Normas Subsidiarias del municipio de Gáldar. Texto refundido. Anexo V a la memoria, pág. 23

27 Publicado en el Boletín Oficial de la Provincia de Las Palmas, con fecha 15 de enero de 2001. 
grantes de esta Junta de Compensación, entre los que se encontraba D. Félix Santiago Melián, como mayor propietario del terreno, vendieron a la empresa inmobiliaria de este propietario (F. S.M. S.L.), la totalidad del mismo. No obstante habrá que esperar hasta el año 2005 para que esta empresa inmobiliaria construya allí la urbanización residencial llamada «La Guancha», la cual está formada únicamente por 46 viviendas en dúplex, dispuestas en hilera que aparecen, únicamente rodeadas de viales con farolas sin construirse los equipamientos urbanos comerciales, escolares, deportivos, culturales, zonas verdes, etc., que debían de acompañar a las mismas como estaba especificado en el Convenio Urbanístico, posteriormente integrado en la publicación definitiva de la Revisión de las Normas Subsidiarias de Planeamiento del Municipio de Gáldar del 1997, y así continúan en el momento actual (2012) dónde todavía queda a la venta una de esas viviendas que consta de $322 \mathrm{~m}^{2}$, distribuidos en dos plantas para la residencia más otra dedicada a garaje con tres plazas, a un precio de 300.000 euros (fotografía 1). Incluso en el momento actual en los alrededores a la nueva urbanización residencial construida en el año 2005, todavía se pueden contemplar antiguos almacenes en donde se realizaban las labores de empaquetado de los plátanos con vistas a la exportación a través

\section{FOTOGRAFÍA 1}

\section{URBANIZACIÓN «LA GUANCHA»EN «EL AGUJERO»(GÁLDAR)}

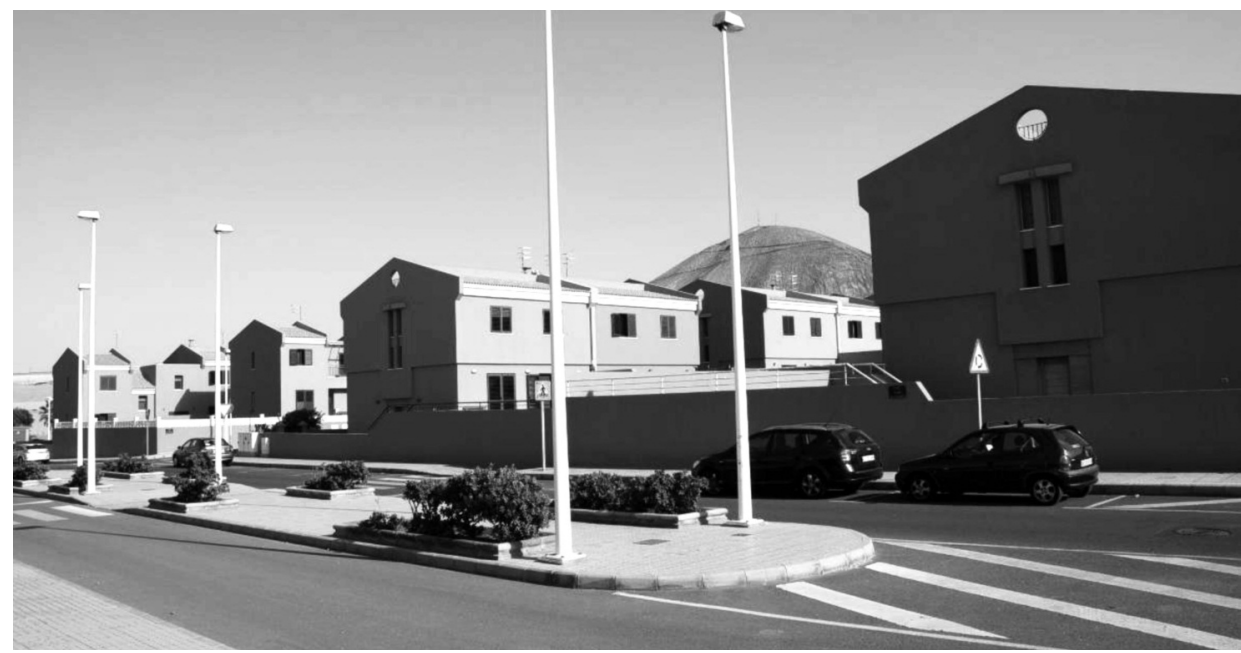

Nota: construcción de viviendas residenciales pareadas en hilera. No existe dotación de equipamientos. Fuente: María Mercedes Arranz Lozano, diciembre 2010. 
del puerto de La Luz en la ciudad de Las Palmas (Torrent, Amador y Suárez, 1995) (fotografía 2).

Con la firma de este Convenio Urbanístico el propietario del terreno y al mismo tiempo su promotor inmobiliario, conseguía la recalificación del suelo rural en urbano, dirigiendo la planificación municipal en este sector hacia la consecución de sus fines particulares, con la connivencia de la administración y poderes locales. Asimismo, se originaba la recalificación de fincas rústicas, pertenecientes al principal propietario del suelo tradicional en Gáldar, dedicadas hasta aquel momento al cultivo intensivo de plataneras, en urbanizables. Lo mismo ocurrió en otros municipios de las Islas Canarias, como fue el caso de La Orotava en la isla de Tenerife (Martín Martín y Jerez Darías, 2011).

El uso cada vez más frecuente de firmar Convenios Urbanísticos entre promotores inmobiliarios y el Alcalde directamente, sin necesidad de autoriza-

\section{FOTOGRAFía 2}

INSTALACIONES INDUSTRIALES CREADAS A COMIENZOS DEL SIGLO XX EN «EL AGUJERO»

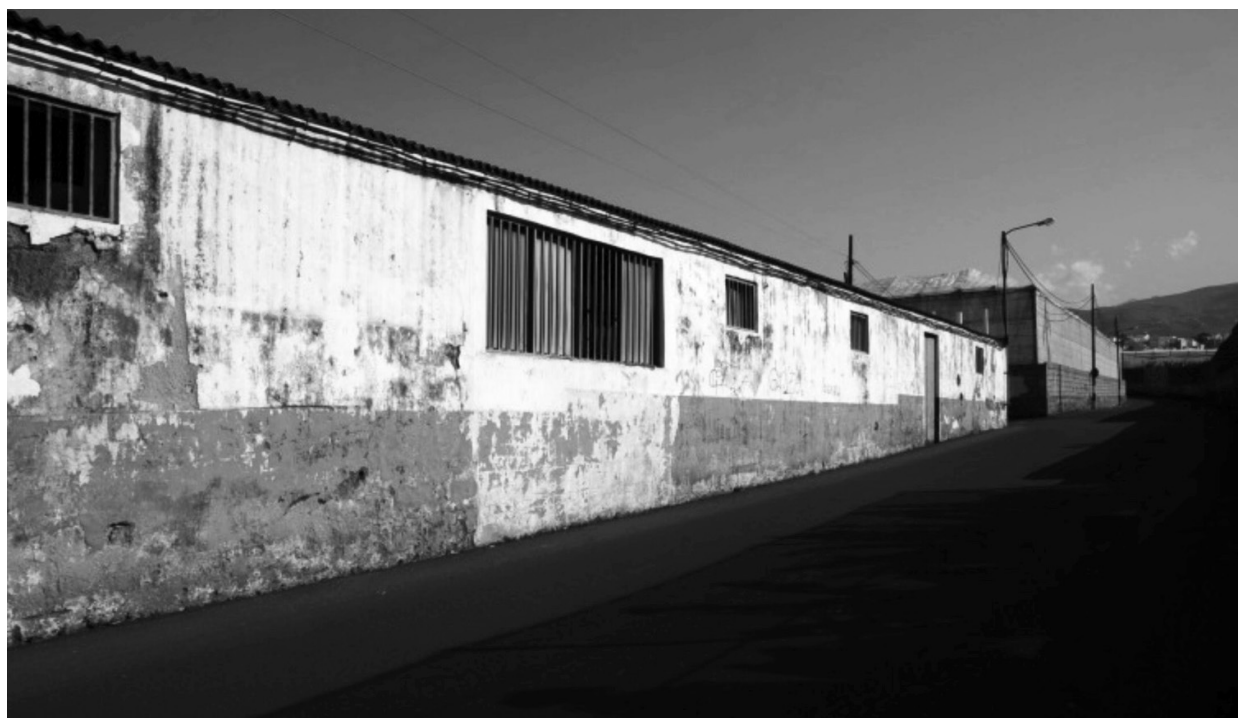

Nota: se trata de antiguos almacenes dedicados al empaquetado de los plátanos con vistas a su exportación hacia Inglaterra. Obsérvese en la parte superior de la fotografía la existencia de una nave cubierta de plásticos correspondiente al cultivo de los plátanos en invernaderos.

Fuente: María Mercedes Arranz Lozano, diciembre 2010. 
ción por el Pleno dificultaba, aún más la labor de control de la oposición política y sí demuestra la especulación y la alianza entre el poder local y los propietarios del suelo. Por esta razón la firma en concreto de este Convenio Urbanístico en Gáldar y su posterior desarrollo urbanístico sí que se puede integrar como un ejemplo más de lo que algunos autores han descrito como un problema de potencial corrupción urbanística en España que obedece a la confluencia de tres tipos de factores: singularidad del modelo urbanístico español, deficiente funcionamiento de los mecanismos de control de la actividad de los Ayuntamientos y extraordinario auge de la construcción de viviendas en el decenio 1998-2008 (Jiménez Sánchez, 2008).

Al mismo tiempo la firma de Convenios Urbanísticos ha servido para que la decisión de los propietarios del suelo — promotores inmobiliarios- buscando su interés particular, haya determinado en esta ocasión la dirección de la expansión urbana y la disposición de un nuevo plano en Gáldar. Este hecho no es nuevo en el crecimiento de las ciudades y es muy semejante al que se realizó con el proceso de configuración de «las Parcelaciones», originado en la mayor parte de las ciudades españolas, a partir de la segunda mitad del siglo XIX, en el que «las iniciativas de los propietarios y sus decisiones afectaron profundamente a la dirección de la expansión urbana y a la configuración del plano» (Arranz Lozano, 1990; Capel, 2002).

\section{El nuevo Plan General de Ordenación Urbana de Gáldar}

En los primeros años del siglo xxi comienza a redactarse lo que será el Nuevo Plan General de Ordenación Urbana del municipio de Gáldar, como «un instrumento de ordenación urbanística de carácter integral del territorio del municipio de Gáldar, según determina el Decreto Legislativo 1/2000, de 8 de mayo, por el que se aprueba el Texto Refundido de las Leyes de Ordenación del Territorio de Canarias y de Espacios Naturales de Canarias (de ahora en adelante TRLOTENC'O0) y su modificación por la Ley 19/2003 de 14 de Abril, de Directrices de Ordenación General y del Turismo de Canarias» ${ }^{28}$.

Este nuevo Plan se tramitó como uno de los que se estaban desarrollando por esos años en Canarias (Jerez Darias, 2004) y en otras Comunidades Autónomas españolas, como por ejemplo la valenciana, donde la mayoría de los planes urbanísticos iniciaron su tramitación en 2005-2006, es decir en la

${ }^{28}$ Plan General de Ordenación de Gáldar (2006): Ordenación Estructural. Normas Urbanísticas. Disponible en: http://www.galdar.es:8081/Galdar/ayuntamiento/ 
cresta de la «Ola Inmobiliaria» y en la que, a pesar que desde 2007 la crisis ha paralizado la actividad constructora, continuaron avanzando en su tramitación sin modificar su expansivo planteamiento (Burriel, 2009).

En este nuevo Plan de Gáldar se recogen de nuevo al menos dieciséis nuevos Convenios Urbanísticos firmados entre el Ayuntamiento y entidades privadas, lo que significa una muestra más de la importancia que sigue teniendo esta figura normativa en la expansión urbana de los municipios españoles. En dicho Plan, «El Agujero» queda calificado ahora como «sector urbanizable sectorizado ordenado, residencial-7 (SUSO-R-7)», presentando una mayor superficie dentro de la misma área $\left(124.750 \mathrm{~m}^{2}\right)$, la cual se construiría más adelante, en Fases II y III, de lo ya urbanizado. De igual modo, si en el documento «La Revisión de las Normas Subsidiarias de 1997» se aprobó, para este sector una densidad de 17 viviendas/ha, ahora se propone 23,33 viviendas /ha; si el coeficiente de edificabilidad entonces era de $0,25 \mathrm{~m}^{2} / \mathrm{m}^{2}$, ahora se presenta como de $0,34 \mathrm{~m}^{2} / \mathrm{m}^{2}$; si el número máximo era de 212 viviendas, ahora es de 291 y si la superficie construida total era de $31.187 \mathrm{~m}^{2}$, ahora es de $41.971,10 \mathrm{~m}^{2}$, señalándose que la primera fase ejecutada ha ocupado $6.617 \mathrm{~m}^{2}$ (Compárese la figura 4 con la figura 5).

El 20 de julio de 2006, fue aprobado de manera definitiva parcial este nuevo Plan General de Ordenación Urbana de Gáldar ${ }^{29}$ y así se encuentra en el momento actual. La aprobación definitiva total no termina de llegar, porque existen informes negativos redactados por técnicos de las Consejerías de Agricultura, Ganadería, Pesca y Alimentación y de la de Ordenación del Territorio y Medio Ambiente de Canarias (COTMAC), porque el Plan no se adapta a la ley de Ordenación del Territorio y Espacios Naturales de Canarias y a la ley de Directrices Generales y del Turismo de Canarias (TRLOTENC) debido a las deficiencias que presenta, entre las cuales se señalan las siguientes: «El SUSO R-7, El Agujero, de $124.750 \mathrm{~m}^{2}$ de superficie es desproporcionada respecto al suelo agrícola colindante y parte sobre suelo agrícola en producción, en zona de alta productividad, por lo que se propone una nueva delimitación ajustadas a las necesidades reales y al uso actual de este suelo» ${ }^{30}$. De la misma manera la COTMAC manifiesta realizar «.... modificaciones en la tipología y normativa específica de Las manzanas en el SUSO R-7 ${ }^{31}$ (figura 5).

29 Véase nota 17.

${ }^{30}$ Informe técnico redactado por el Ingeniero agrónomo de la Dirección General de Estructuras agrarias y Jefe de la Sección de Ordenación Rural de Las Palmas, firmado, en Las Palmas, el 10 de mayo de 2006, p. 2.

${ }^{31}$ Informe de la sesión celebrada el 20 de julio de 2006 de la Consejería de Medio Ambiente y Ordenación Territorial de Canarias (COTMAC), p. 8. 
FIGURAS 5

SECTOR SUSO-R-7- «EL AGUJERO»

(SUELO URBANIZABLE SECTORIZADO ORDENADO)

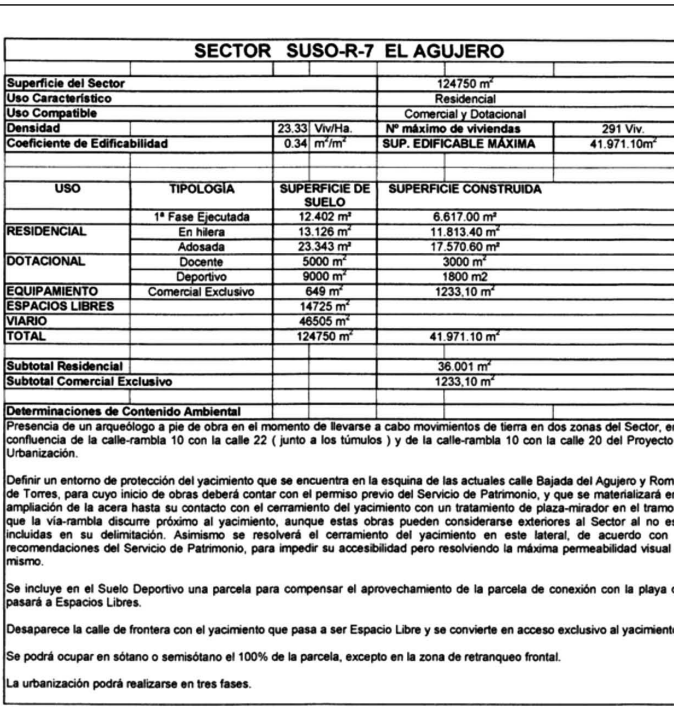

Las Medidas correctoras de carácter ambiental aplicables a este sector son las definidas en las fichas Memoria de Ordenación.

Este sector se desarrollará por sistema de ejecución privado

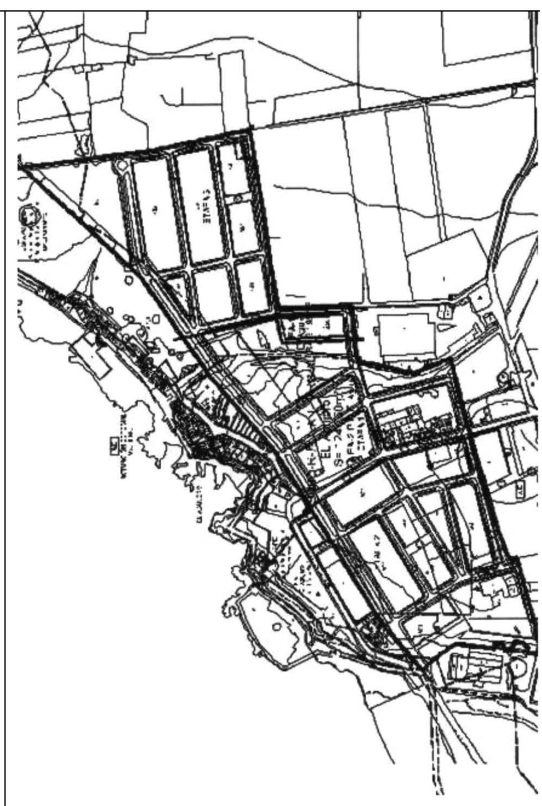

Fuente: Plan General de Ordenación de Gáldar (2006): Ordenación Estructural. Normas Urbanísticas (http://www.galdar.es:8081/Galdar/ayuntamiento/).

Asimismo hay varias fincas de suelo integradas dentro de este SUSO-R-7, que se prevén como "Suelo urbano no consolidado SUNC», aunque tienen un uso agrícola. Incluso en ellas se encuentra la denominada Unidad de Actuación (UA) EA-2, en la que se prevé una extensión de 12.179 has, de usos residencial y comercial, con una densidad de 51 viviendas/ha, y en donde se señala que el espacio libre de dicha Unidad se integrará «....en una parcela propiedad del municipio dentro de lo que constituirá el Sistema General Arqueológico de Bocabarranco, cuya ejecución se realizará a través de Plan Especial o en su caso proyecto de obra de conjunto arqueológico»32. Todas estas actuaciones han sido rechazadas por la COTMAC, constituyendo elementos lo suficientemente significativos como para que el Plan General de Ordena-

32 Plan General de Ordenación Urbana de Gáldar, Unidad de Actuación El Agujero EA-2. 
ción Urbana de Gáldar no alcance la aprobación definitiva hasta que no se corrijan estas previsiones urbanísticas (figura 5).

Vemos, pues, que lo que empezó siendo un Convenio Urbanístico firmado por un propietario del suelo y el Alcalde en el año 1994, se ha ido consolidando de tal manera que al final es la intención de construcción urbanística de las fincas de este propietario lo que realmente se consigue, adecuándose la normativa urbana establecida posteriormente a la intención de dicho propietario-promotor inmobiliario, y conseguir así urbanizar un sector alejado del centro urbano, el cual había tenido tradicionalmente un uso rural de explotación de plátanos. Este proceso de urbanización en «El Agujero» se va a seguir consolidando con la aprobación del nuevo Plan. De hecho, en el momento presente, el promotor de la urbanización, edificada en 2005, ya tiene preparados los terrenos y los materiales para construir lo que será la segunda fase de la misma, sobre «Suelo urbanizable sectorizado ordenado SUSO R-7» permitido en el Plan, el cual se situará justo enfrente de la anterior (fotografía 4).

De todas las fincas rústicas, dedicadas a la explotación de plátanos en el sector de «El Agujero», D. Félix Santiago, como ya se ha señalado anteriormente, compró en el año 1992 a la «Sociedad Cooperativa Herederos de Mr.

\section{FOTOGRAFÍA 3}

\section{URBANIZACIÓN «LA GUANCHA»EN «EL AGUJERO»Y SOLARES URBANOS}

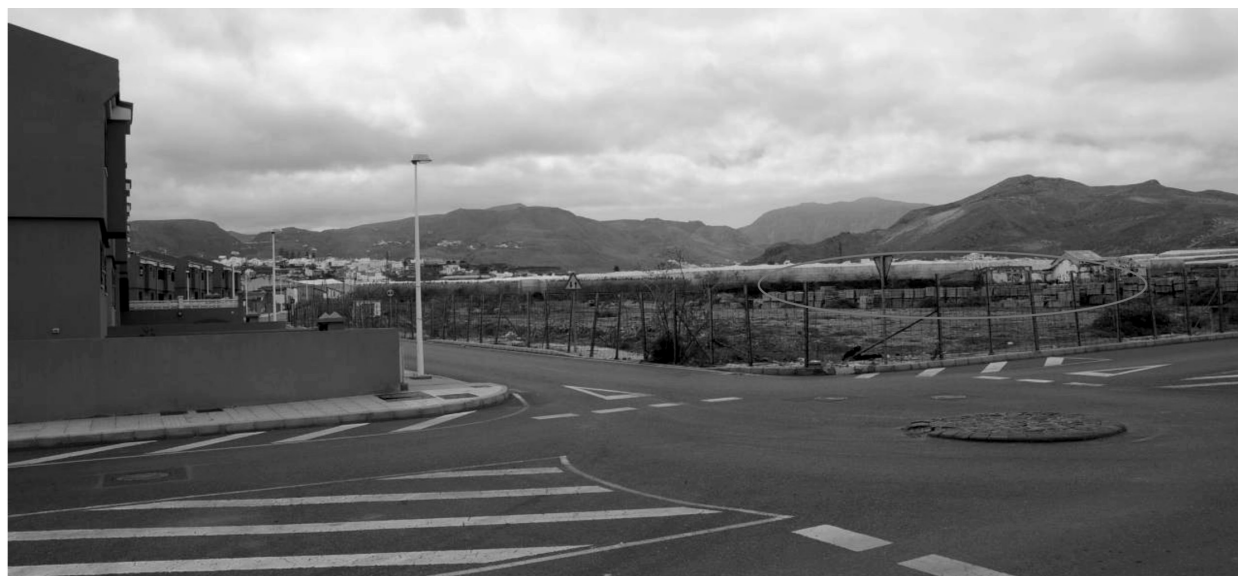

Nota: a la izquierda se observa el perfil de las viviendas residenciales de la urbanización «La Guancha» en el Agujero ya consolidadas. En el solar de enfrente se encuentran preparados los materiales para la construcción de la nueva fase.

Fuente: María Mercedes Arranz Lozano, marzo 2011. 
Leacook» una gran parte de las mismas, transformando el uso del suelo, de agrícola a urbano. Así se construyó la primera fase de la urbanización La Guancha, en 2005. En el momento presente ya está explanado el terreno adjunto para construir la segunda fase de la urbanización (fotografía 3). Mientras tanto, fincas suyas dedicadas al cultivo intensivo del plátano, para cuya explotación recibe ayudas económicas de Europa, se encuentran situadas a continuación del terreno ya urbanizado. Serán estas fincas las que se desmontarán para construir la tercera fase de la urbanización, cuando quede aprobado definitivamente el Plan General de Ordenación Urbana de Gáldar (fotografía 4).

En esta misma fotografía 4 se observa, en la imagen de la izquierda, el cordón que bordea la costa en donde se sitúan los yacimientos arqueológicos de «La Guancha», El «Agujero» y «Bocabarranco». Sobre ellos, de acuerdo a lo formulado en el nuevo Plan del 2006, se debería aprobar un plan especial de conservación de esos mismos espacios, los cuales a su vez constituirían el espacio libre de la urbanización «La Guancha». Este planteamiento ha sido desestimado por la COTMAC.

Los propietarios del suelo en Guía-Gáldar, que se constituían al mismo tiempo en promotores inmobiliarios, han marcado la expansión urbana del municipio en función de sus intereses; éstos empezaron siendo propietarios de algunas fincas rurales - de cultivos de plataneras-y con el tiempo cambiaron el uso del suelo, a la vez que fueron agrandando su patrimonio inmobiliario, comprando más fincas a bajo precio cuando se presentaba la oportunidad. Este tipo de «nuevos» promotores inmobiliarios surgió en muchos municipios de las islas Canarias, en el proceso rápido que supuso el paso de una economía basada en el sector agrario a otra fundamentada en el sector turístico e inmobiliario, lo que originó, entre otras cosas, el «predominio de pretensiones urbanizadoras-inmobiliarias, caracterizadas en su mayoría por ser individuales, anacrónicas y aisladas, al no estar ligadas a un proyecto de explotación conjunto» (Simancas, 2010).

Estos propietarios del suelo, promotores inmobiliarios, ya tenían una gran connivencia, en su quehacer, con alcaldes franquistas de los municipios, la cual se fue afianzando todavía más con la llegada del PSOE a los Ayuntamientos; dichas relaciones se consolidaron aún más, controlando poco a poco no sólo el poder político local - Ayuntamientos, Cabildos- sino también el de la Comunidad Autónoma, instituciones que elaboraban y sancionaban las calificaciones del suelo urbano y urbanizable (Martín Martín, 1999). Asimismo, la aprobación del Decreto 156/1994, de 21 de julio, «De transferencias de funciones de la Administración Pública de la Comunidad Autónoma de Canarias a los Cabildos Insulares en materia de promoción y policía del turismo insu- 


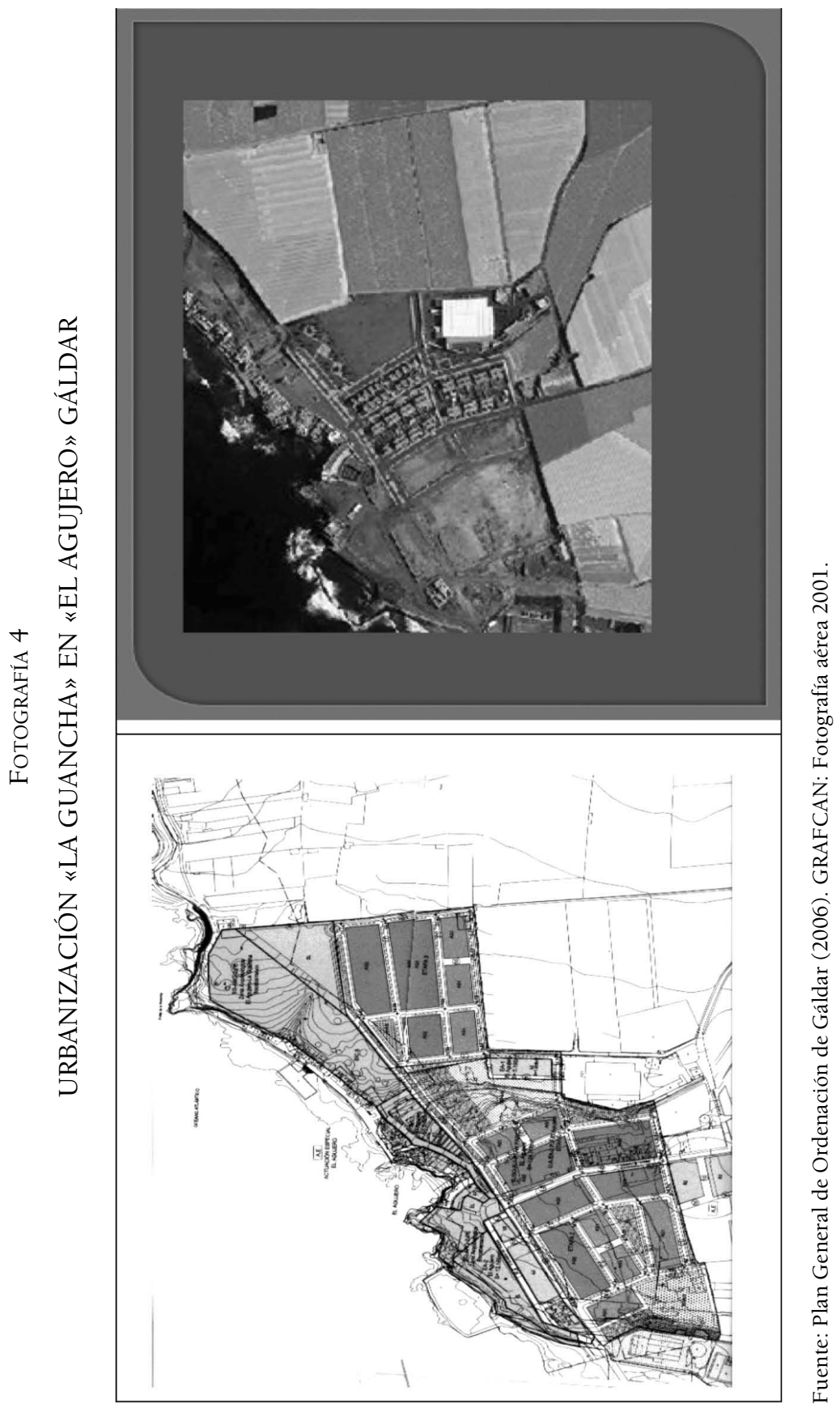

Estudios Geográficos, Vol. LXXIV, 274, pp. 7-44, enero-junio 2013 ISSN: 0014-1496, eISSN: 1988-8546, doi: 10.3989/estgeogr.201301 
lar», vino a otorgar, el traspaso de competencias en materia de urbanismo a los Ayuntamientos (Simancas, 2010) y con ello estrechaba más sus magníficas relaciones en materia de aprovechamiento y producción de suelo urbano entre el gobierno local y los agentes privados (Tinaut Elorza, 2006).

\section{A MODO DE CONCLUSIÓN}

El Convenio Urbanístico constituye una figura legal que aparece recogida en La Ley 7/1985, de 2 de abril, Reguladora de las Bases del Régimen Local (LBRL), que se establece siempre a partir de la firma el Alcalde, como representante del Ayuntamiento y un particular - persona física o jurídica- y no tiene la obligación de ser aprobado por el Pleno del Gobierno Local, lo cual dificulta la labor de control de la oposición política.

La construcción de la urbanización residencial «La Guancha» en el sector espacial «El Agujero» en Gáldar, se realizó mediante la firma de un Convenio Urbanístico en el año 1994 y constituye uno de los muchos ejemplos utilizados en España para la construcción de conjuntos inmobiliarios residenciales que han sido previstos con anterioridad a la aprobación de un plan municipal de urbanización.

Esta figura legal ha sido utilizada de manera interesada y conjunta por la administración local y los propietarios del suelo para llevar a cabo una extensión urbana de Gáldar, ya desde el año 1994 hasta la actualidad para configurar el crecimiento urbano de este municipio de acuerdo a la consecución de intereses particulares.

La construcción de dicha urbanización alejada del casco fundacional ha trazado una nueva dirección de la expansión urbana así como la disposición de un nuevo plano en desarrollo urbanístico de Gáldar. Este proceso de crecimiento urbano no es nuevo en las ciudades españolas, sino que ya se pudo observar en muchas de ellas desde la segunda mitad del siglo xIX, a partir de la configuración de las llamadas «Parcelaciones».

Por otra parte, la enredada maraña de legislación sobre ordenación del territorio que se ha ido generando en la Comunidad Canaria, desde comienzos de los años noventa, ha ayudado a originar en muchos municipios de las islas un desarrollo urbanístico desaforado que, en la muchos casos han sido objeto de litigio que se están dirimiendo en los juzgados, como ha sido puesto de manifiesto por diversos juristas especializados en esta materia.

Fecha de recepción: 04/07/2011

Fecha de aceptación: 02/04/2012 
Anexos:

Cuadro 2

LEGISLACIÓN SOBRE URBANIZACIÓN, ORDENACIÓN DEL SUELO, MEDIO AMBIENTE Y TURISMO QUE AFECTA AL PROCESO DE URBANIZACIÓN EN LAS ISLAS CANARIAS

\begin{tabular}{|c|c|c|}
\hline Tipo & Número & Nombre \\
\hline Real Decreto & $\begin{array}{l}\text { 2843/1979, } \\
\text { de } 7 \text { de diciembre }\end{array}$ & $\begin{array}{l}\text { Por el que se transfieren a la Comunidad Autó- } \\
\text { noma de Canarias, competencias en materia de } \\
\text { Administración Local. }\end{array}$ \\
\hline LEY ORGÁNICA & $\begin{array}{l}\text { 10/1982, } \\
\text { de } 10 \text { de agosto }\end{array}$ & $\begin{array}{l}\text { Estatuto Autonomía de la Comunidad Autó- } \\
\text { noma de Canarias. } \\
\text { Publicado en B.O.E. 16-8-1982, núm. 195, y en } \\
\text { B.O. CANARIAS 28-9-1982, núm. } 17 .\end{array}$ \\
\hline LEY ORGÁNICA & $\begin{array}{l}\text { 11/1982, } \\
\text { de } 10 \text { de agosto }\end{array}$ & De transferencias Complementarias a Canarias. \\
\hline Ley & $\begin{array}{l}\text { 1/1983, } \\
\text { de } 14 \text { de abril }\end{array}$ & $\begin{array}{l}\text { De Gobierno y Administración Pública de Cana- } \\
\text { rias. }\end{array}$ \\
\hline Ley & $\begin{array}{l}\text { 50/1985, } \\
\text { de } 27 \text { de diciembre }\end{array}$ & De Incentivos Regionales. \\
\hline $\begin{array}{l}\text { Real Decreto } \\
\text { Legislativo }\end{array}$ & $\begin{array}{l}\text { 781/1986, } \\
\text { de } 18 \text { de abril }\end{array}$ & $\begin{array}{l}\text { Texto Refundido de Disposiciones legales vigen- } \\
\text { tes en materia de Régimen Local. }\end{array}$ \\
\hline Real Decreto & $\begin{array}{l}\text { 1372/1986, } \\
\text { de } 13 \text { de junio }\end{array}$ & Reglamento de bienes de Entidades Locales. \\
\hline $\begin{array}{l}\text { Real Decreto } \\
\text { Legislativo }\end{array}$ & $\begin{array}{l}\text { 1302/1986, } \\
\text { de } 28 \text { de junio. }\end{array}$ & De Evaluación de Impacto Ambiental. \\
\hline Real Decreto & $\begin{array}{l}2568 / 1986, \\
\text { de } 28 \text { de noviembre }\end{array}$ & $\begin{array}{l}\text { Por el que se aprueba el Reglamento de Organi- } \\
\text { zación, Funcionamiento y Régimen jurídico de } \\
\text { las Entidades Locales. }\end{array}$ \\
\hline Ley & $\begin{array}{l}\text { 5/1987, } \\
\text { de } 7 \text { de abril }\end{array}$ & $\begin{array}{l}\text { Sobre la Ordenación Urbanística del Suelo Rús- } \\
\text { tico de la Comunidad Autónoma de Canarias. }\end{array}$ \\
\hline Ley & $\begin{array}{l}\text { 6/1987, } \\
\text { de } 7 \text { de abril }\end{array}$ & $\begin{array}{l}\text { Sobre el sistema de Actuación de urbanización } \\
\text { diferida. }\end{array}$ \\
\hline Real Decreto & $\begin{array}{l}\text { 1535/1987, } \\
\text { de } 11 \text { de diciembre }\end{array}$ & $\begin{array}{l}\text { Por el que se aprueba el Reglamento de la Ley } \\
50 / 1985 \text { de } 27 \text { de diciembre, de Incentivos Re- } \\
\text { gionales para la corrección de desequilibrios } \\
\text { económicos interterritoriales (casi la totalidad } \\
\text { de subvenciones a fondo perdido concedidas en } \\
\text { Canarias desde 1996-2002) en materia de tu- } \\
\text { rismo. }\end{array}$ \\
\hline Real Decreto & $\begin{array}{l}\text { 569/1988, } \\
\text { de } 3 \text { de junio }\end{array}$ & $\begin{array}{l}\text { De delimitación de la zona de promoción eco- } \\
\text { nómica de Canarias (vigente hasta } 1 \text { de enero de } \\
\text { 2007). }\end{array}$ \\
\hline
\end{tabular}




\begin{tabular}{|c|c|c|}
\hline Tipo & Número & Nombre \\
\hline Ley & $\begin{array}{l}22 / 1988, \\
\text { de } 28 \text { de julio }\end{array}$ & De Costas y su reglamento. \\
\hline Real Decreto & $\begin{array}{l}\text { 1131/1988, } \\
\text { de } 30 \text { de septiembre }\end{array}$ & $\begin{array}{l}\text { Reglamento de ejecución del Real Decreto Le- } \\
\text { gislativo 1302/1986, de } 28 \text { de junio de Evalua- } \\
\text { ción de Impacto Ambiental. }\end{array}$ \\
\hline Ley & $\begin{array}{l}\text { 39/1988, } \\
\text { de } 28 \text { de diciembre }\end{array}$ & $\begin{array}{l}\text { Reguladora de Haciendas Locales, que posibilitó } \\
\text { que los municipios se dotasen de una estructura } \\
\text { recaudatoria propia basada en la imposición so- } \\
\text { bre el suelo (en concreto la capacidad de califi- } \\
\text { carlo) en su doble mecanismo tributario de } \\
\text { tenencia y plusvalías, con el fin de asegurar un } \\
\text { grado aceptable de autonomía fiscal. }\end{array}$ \\
\hline Decreto & $\begin{array}{l}\text { 165/1989, } \\
\text { de } 17 \text { de julio }\end{array}$ & $\begin{array}{l}\text { Por el que establecen los requisitos de infraes- } \\
\text { tructuras en alojamientos turísticos. }\end{array}$ \\
\hline Real Decreto & $\begin{array}{l}\text { 1471/89, } \\
\text { de } 1 \text { de diciembre }\end{array}$ & Reglamento de la Ley de Costas. \\
\hline Ley & $\begin{array}{l}\text { 11/1990, } \\
\text { de } 13 \text { de julio }\end{array}$ & $\begin{array}{l}\text { De Prevención de Impacto Ecológico de la Co- } \\
\text { munidad Autónoma de Canarias. }\end{array}$ \\
\hline Ley & $\begin{array}{l}\text { 14/1990, } \\
\text { de } 26 \text { de julio }\end{array}$ & $\begin{array}{l}\text { De reforma de la Ley } 8 / 1986 \text {, de } 18 \text { de noviem- } \\
\text { bre, de Régimen Jurídico de las Administraciones } \\
\text { Públicas de Canarias. }\end{array}$ \\
\hline Ley & $\begin{array}{l}\text { 30/1992, } \\
\text { de } 26 \text { de noviembre }\end{array}$ & $\begin{array}{l}\text { De Régimen Jurídico de las Administraciones } \\
\text { Públicas y del Procedimiento Administrativo } \\
\text { Común. }\end{array}$ \\
\hline Ley & $\begin{array}{l}\text { 19/1994, } \\
\text { de } 6 \text { de julio }\end{array}$ & $\begin{array}{l}\text { De modificación del Régimen Económico y Fis- } \\
\text { cal de Canarias. (RIC= constituye uno de los re- } \\
\text { cursos financieros más potentes de los que } \\
\text { conforman el Régimen Económico y Fiscal de } \\
\text { Canarias. }\end{array}$ \\
\hline Decreto & $\begin{array}{l}\text { 156/1994, } \\
\text { de } 21 \text { de julio }\end{array}$ & $\begin{array}{l}\text { De transferencias de funciones de la Adminis- } \\
\text { tración Pública de la Comunidad Autónoma de } \\
\text { Canarias a los Cabildos Insulares en materia de } \\
\text { promoción y policía del turismo insular. }\end{array}$ \\
\hline Ley & $\begin{array}{l}\text { 12/1994, } \\
\text { de } 19 \text { de diciembre }\end{array}$ & $\begin{array}{l}\text { Territorial de Espacios Naturales de Canarias } \\
\text { (L.E.N.A.C.). }\end{array}$ \\
\hline Decreto & $\begin{array}{l}35 / 1995 \\
\text { de } 24 \text { de febrero }\end{array}$ & $\begin{array}{l}\text { Reglamento de contenido ambiental de los in- } \\
\text { strumentos de planeamiento (BOC, } \mathrm{n}^{\circ} 36 \text { de } \\
\text { 24.03.1995) (Legislación sectorial de apli- } \\
\text { cación). }\end{array}$ \\
\hline Decreto & $\begin{array}{l}\text { 7/1995, } \\
\text { de } 27 \text { de enero y } \\
42 / 1995 \text {, } \\
\text { de } 10 \text { de marzo }\end{array}$ & $\begin{array}{l}\text { Se aprueba definitivamente el Plan Insular de Or- } \\
\text { denación de Gran Canaria (PIOGC). }\end{array}$ \\
\hline
\end{tabular}




\begin{tabular}{|c|c|c|}
\hline Tipo & Número & Nombre \\
\hline Ley & 7/1995, de 6 de abril & De Ordenación del Turismo de Canarias (LOT). \\
\hline Decreto & $\begin{array}{l}\text { 321/1995, } \\
\text { de } 10 \text { de noviembre }\end{array}$ & $\begin{array}{l}\text { Reglamento Orgánico de la Consejería de Presi- } \\
\text { dencia y Relaciones Institucionales de la Comu- } \\
\text { nidad Autónoma de Canarias. }\end{array}$ \\
\hline Decreto & $\begin{array}{l}\text { 6/1997, } \\
\text { de } 21 \text { de enero }\end{array}$ & $\begin{array}{l}\text { Por el que se fijan las directrices formales para la } \\
\text { elaboración de los Planes de Ordenación de los } \\
\text { recursos naturales. }\end{array}$ \\
\hline Ley & $\begin{array}{l}4 / 1999, \\
\text { de } 15 \text { de marzo }\end{array}$ & De Patrimonio Histórico de Canarias. \\
\hline Ley & $\begin{array}{l}\text { 9/1999, } \\
\text { de } 15 \text { de mayo }\end{array}$ & $\begin{array}{l}\text { De Ordenación del Territorio de Canarias, que } \\
\text { posteriormente se convirtió en el Texto Refun- } \\
\text { dido de las Leyes de Ordenación del Territorio y } \\
\text { de Espacios Naturales de Canarias, por mandato } \\
\text { de la citada ley y por medio del Decreto Legisla- } \\
\text { tivo } 1 / 2000 \text {. }\end{array}$ \\
\hline $\begin{array}{l}\text { Decreto } \\
\text { Legislativo }\end{array}$ & $\begin{array}{l}1 / 2000 \\
\text { de } 8 \text { de mayo } \\
\text { TRLOTENC }\end{array}$ & $\begin{array}{l}\text { Por el que se aprueba el Texto refundido de las } \\
\text { Leyes de Ordenación del Territorio de Canarias } \\
\text { y de Espacios Naturales de Canarias (BOC, } \mathrm{n}^{\circ} \\
60 \text { de } 15.05 .2000 \text { ). } \\
\text { Este Decreto refunde las disposiciones de: } \\
\text { - La Ley 9/1999, de } 13 \text { de mayo, de Ordenación } \\
\text { del Territorio de Canarias. } \\
\text { - Ley } 12 / 1994 \text {, de } 19 \text { de diciembre, de Espacios } \\
\text { Naturales de Canarias. } \\
\text { - Ley 13/1994 de } 22 \text { de diciembre de Modifi- } \\
\text { cación del Anexo de la Ley anterior. }\end{array}$ \\
\hline Decreto & $\begin{array}{l}55 / 2000 \\
\text { de } 10 \text { de abril }\end{array}$ & $\begin{array}{l}\text { Por el que se establece el plazo para la adapta- } \\
\text { ción del planeamiento urbanístico municipal de } \\
\text { Gran Canaria al Plan Insular (PIOGC). }\end{array}$ \\
\hline Ley & $\begin{array}{l}2 / 2000 \\
\text { de } 17 \text { de julio }\end{array}$ & $\begin{array}{l}\text { De medidas económicas en materia de organi- } \\
\text { zación administrativa y gestión relativas al per- } \\
\text { sonal de la Comunidad Autónoma de Canarias y } \\
\text { establecimiento de normas tributarias. (BOC, } \text { n }^{\circ} \\
94 \text { de 28.07.2000). } \\
\text { Transferencia de competencias en materia de } \\
\text { turismo y transporte a los Cabildos Insulares. }\end{array}$ \\
\hline Decreto & $\begin{array}{l}4 / 2001, \\
\text { de } 15 \text { de enero }\end{array}$ & $\begin{array}{l}\text { Por el que se acuerda la formulación de las Direc- } \\
\text { trices de Ordenación General y del Turismo de } \\
\text { Canarias (B.O.C. n }{ }^{\circ} 7 \text { de 15.01.2001). (Dero- } \\
\text { gado). }\end{array}$ \\
\hline Ley & $\begin{array}{l}6 / 2001 \\
\text { de } 23 \text { de julio }\end{array}$ & $\begin{array}{l}\text { De medidas urgentes en materia de Ordenación } \\
\text { del territorio y del turismo en Canarias. (Primera } \\
\text { moratoria). }\end{array}$ \\
\hline
\end{tabular}




\begin{tabular}{|c|c|c|}
\hline Tipo & Número & Nombre \\
\hline Decreto & $\begin{array}{l}\text { 127/2001, } \\
\text { de } 5 \text { de julio }\end{array}$ & $\begin{array}{l}\text { Por el que se regulan las Directrices de Orde- } \\
\text { nación. }\end{array}$ \\
\hline Decreto & $\begin{array}{l}\text { 176/2001, } \\
\text { de } 6 \text { de septiembre }\end{array}$ & $\begin{array}{l}\text { Por el que se acuerda el inicio de la elaboración } \\
\text { de las Directrices de Ordenación General y de } \\
\text { Turismo. }\end{array}$ \\
\hline Directiva & $\begin{array}{l}\text { 2001/42/CE DEL } \\
\text { Parlamento Europeo } \\
\text { y del Consejo Eu- } \\
\text { ropeo de } 27 \text { de junio } \\
\text { de } 2001\end{array}$ & $\begin{array}{l}\text { Evaluación de los efectos de determinados } \\
\text { planes y programas en el medio ambiente (Di- } \\
\text { ario Oficial, } \mathrm{n}^{\circ} \text { L 197, de 21.07.2001). }\end{array}$ \\
\hline Ley & $\begin{array}{l}6 / 2002, \\
\text { de } 12 \text { de junio }\end{array}$ & $\begin{array}{l}\text { Sobre medidas de ordenación territorial, de la } \\
\text { actividad turística en las islas de El Hierro, La } \\
\text { Gomera, La Palma. (Segunda moratoria turís- } \\
\text { tica). }\end{array}$ \\
\hline Ley & $\begin{array}{l}\text { 19/2003, } \\
\text { de } 14 \text { de abril }\end{array}$ & $\begin{array}{l}\text { Por la que se aprueban las Directrices de Orde- } \\
\text { nación General y las Directrices de Ordenación } \\
\text { de Turismo de Canarias, también conocida } \\
\text { como La Moratoria (Segunda moratoria) que } \\
\text { recogen y complementan a la realidad territorial } \\
\text { Canaria los principios generales de sostenibili- } \\
\text { dad formulados a nivel internacional y estatal. } \\
\text { (B.O.C. } \mathrm{n}^{\circ} 73 \text { de 15.04.2003). }\end{array}$ \\
\hline Decreto & $\begin{array}{l}\text { 277/2003, } \\
\text { de } 11 \text { de noviembre }\end{array}$ & $\begin{array}{l}\text { Por el que se aprueba definitivamente el Plan } \\
\text { Insular de Ordenación de Gran Canaria } \\
\text { (PIOGC), a reserva de que se subsanen las defi- } \\
\text { ciencias advertidas por la Comisión de Orde- } \\
\text { nación del Territorio y Medio Ambiente de } \\
\text { Canarias en sesión celebrada el } 20 \text { de mayo de } \\
\text { 2003. }\end{array}$ \\
\hline Ley, & $\begin{array}{l}2 / 2003 \\
\text { de } 30 \text { de enero }\end{array}$ & De Viviendas de Canarias. \\
\hline Decreto & $\begin{array}{l}64 / 2004 \\
\text { de } 25 \text { de mayo }\end{array}$ & $\begin{array}{l}\text { Por el que se subsanan las deficiencias no sus- } \\
\text { tanciales del (PIOGC). }\end{array}$ \\
\hline Ley & $\begin{array}{l}\text { 1/2006, } \\
\text { de } 7 \text { de febrero }\end{array}$ & $\begin{array}{l}\text { De modificación de la Ley } 2 \text { /2003, de } 30 \text { de en- } \\
\text { ero, de Viviendas de Canarias. }\end{array}$ \\
\hline Ley & $\begin{array}{l}\text { 4/2006, } \\
\text { de } 22 \text { de mayo }\end{array}$ & $\begin{array}{l}\text { De modificación del Texto Refundido de las } \\
\text { Leyes de Ordenación del territorio de Canarias y } \\
\text { de Espacios Natrales de Canarias (aprobado por } \\
\text { el Decreto Legislativo 1/2000 de } 8 \text { de mayo). }\end{array}$ \\
\hline Ley & $\begin{array}{l}\text { 9/2006, } \\
\text { de } 28 \text { de abril }\end{array}$ & $\begin{array}{l}\text { Sobre evaluación de los efectos de determinados } \\
\text { planes y programas en el medio ambiente } \\
\text { (B.O.E., N } N^{\circ} 102 \mathrm{DE} 29.04 .2006 \text { ). Aquí en el } \\
\text { art.8.4., viene el Informe de sostenibilidad. }\end{array}$ \\
\hline
\end{tabular}




\begin{tabular}{l|l|l}
\hline Tipo & Número & Nombre \\
\hline Decreto & $\begin{array}{l}55 / 2006, \\
\text { de } 9 \text { de mayo }\end{array}$ & $\begin{array}{l}\text { Por el que se aprueba el Reglamento de proced- } \\
\text { imientos de los instrumentos de Ordenación del } \\
\text { Sistema de Planeamiento de Canarias (B.O.C. } \mathrm{n}^{\circ} \\
104 \text { de 31.05.2006). }\end{array}$ \\
\hline Ley & $\begin{array}{l}\text { 6/2009, } \\
\text { de } 6 \text { de mayo }\end{array}$ & $\begin{array}{l}\text { De Medidas Urgentes en Materia de Ordenación } \\
\text { Territorial para la dinamización sectorial y la } \\
\text { Ordenación del Turismo (tercera y última mora- } \\
\text { toria hasta la actualidad). }\end{array}$ \\
\hline Ley & $\begin{array}{l}\text { De modificación del Texto refundido de las } \\
\text { Leyes de Ordenación del Territorio de Canaria y } \\
\text { de Espacios naturales de Canarias, sobre de- } \\
\text { claración y ordenación de áreas urbanas en el } \\
\text { litoral canario. }\end{array}$ \\
\hline
\end{tabular}

Fuente: elaboración propia a partir de las figuras de legislación urbana de alcance de Comunidad Autónoma y Local (Cabildos). 
Cuadro 3

NORMATIVA SOBRE PLANEAMIENTO URBANO EN LOS MUNICIPIOS GÁLDAR-GUÍA

\begin{tabular}{|c|c|c|}
\hline Tipo & Número & Nombre \\
\hline Hasta 1985 & |----------- & $\begin{array}{l}\text { Normas subsidiarias provinciales que rigen el } \\
\text { crecimiento urbano de ambos municipios. }\end{array}$ \\
\hline $\begin{array}{l}\text { Normas } \\
\text { Subsidiarias }\end{array}$ & $\begin{array}{l}\text { Aprobadas definiti- } \\
\text { vamente por la Comi- } \\
\text { sión Provincial de } \\
\text { urbanismo en sesión } \\
\text { de 21-07-1983. }\end{array}$ & $\begin{array}{l}1^{a} \text { Normas Subsidiarias que se aprueban en el } \\
\text { MUNICIPIO DE STA.M }{ }^{a} \text { DE GUİA, de vigencia } \\
\text { indefinida y para las que no resultaba viable fijar } \\
\text { un plazo exacto para su sustitución por un Plan } \\
\text { General. }\end{array}$ \\
\hline $\begin{array}{l}\text { Normas } \\
\text { Subsidiarias }\end{array}$ & $\begin{array}{l}\text { Aprobadas definiti- } \\
\text { vamente por la Comi- } \\
\text { sión Provincial de } \\
\text { urbanismo en sesión } \\
\text { de 14-11-1985. }\end{array}$ & $\begin{array}{l}1^{a} \text { Normas Subsidiarias que se aprueban en el } \\
\text { MUNICIPIO DE GÁLDAR, de vigencia in- } \\
\text { definida y para las que no resultaba viable fijar } \\
\text { un plazo exacto para su sustitución por un Plan } \\
\text { General. }\end{array}$ \\
\hline Decreto & $\begin{array}{l}\text { 258/1993, } \\
\text { de } 24 \text { de septiembre }\end{array}$ & $\begin{array}{l}\text { En relación con la declaración de bienes o mon- } \\
\text { umentos de interés cultural e histórico o simi- } \\
\text { lar: referido a Barranco Hondo de Abajo, en } \\
\text { Gáldar. }\end{array}$ \\
\hline Decreto & $\begin{array}{l}\text { 261/1993, } \\
\text { de } 24 \text { de septiembre }\end{array}$ & $\begin{array}{l}\text { En relación con la declaración de bienes o mon- } \\
\text { umentos de interés cultural e histórico o simi- } \\
\text { lar: referido a Casa Verde de Aguilar, en Gáldar. }\end{array}$ \\
\hline Decreto & $\begin{array}{l}\text { 39/1994, } \\
\text { de } 8 \text { de abril }\end{array}$ & $\begin{array}{l}\text { En relación con la declaración de bienes o mon- } \\
\text { umentos de interés cultural e histórico o simi- } \\
\text { lares: referido a hacienda de Hoya de Pineda, en } \\
\text { Gáldar. }\end{array}$ \\
\hline $\begin{array}{l}\text { Texto refundido } \\
\text { de la Revisión de } \\
\text { las Normas Sub- } \\
\text { sidiarias en el } \\
\text { municipio de } \\
\text { Gáldar }\end{array}$ & $\begin{array}{l}\text { Aprobación defini- } \\
\text { tiva 28-01-1997 }\end{array}$ & $\begin{array}{l}\text { La revisión de las Normas Subsidiarias del } 85 \text { en } \\
\text { el municipio de Gáldar. Se redactan por la arqui- } \\
\text { tecta Cándida R. Benítez Suárez, con fecha } 15 \text { de } \\
\text { julio de } 1993 \text {, se enmarca dentro del P.I.O.T. de } \\
\text { Gran Canaria y en el desarrollo de la conur- } \\
\text { bación Guía-Gáldar, en el NW de la isla. } \\
\text { Aprobadas inicialmente mayo de 1994; definiti- } \\
\text { vamente y de forma parcial con fecha 09-05- } \\
1996 \text { y definitivamente el 28-01-1997. }\end{array}$ \\
\hline Ley & $\begin{array}{l}\text { 4/1999, } \\
\text { de } 15 \text { de marzo }\end{array}$ & $\begin{array}{l}\text { De Patrimonio histórico modificada por la Ley } \\
\text { 2/2002 de } 27 \text { de marzo de Patrimonio histórico. }\end{array}$ \\
\hline Ley & $\begin{array}{l}\text { 2/2002, } \\
\text { de } 27 \text { de marzo }\end{array}$ & De Patrimonio histórico. \\
\hline Ley & $\begin{array}{l}\text { 19/2003, } \\
\text { de } 14 \text { de abril }\end{array}$ & $\begin{array}{l}\text { Por la que se aprueban las Directrices de Orde- } \\
\text { nación General y las Directrices de Ordenación } \\
\text { de Turismo de Canarias. }\end{array}$ \\
\hline
\end{tabular}




\begin{tabular}{|c|c|c|}
\hline Tipo & Número & Nombre \\
\hline Decreto & $\begin{array}{l}\text { 277/2003, } \\
\text { de } 11 \text { de noviembre }\end{array}$ & $\begin{array}{l}\text { Por el que se aprueba definitivamente el Plan } \\
\text { Insular de Ordenación de Gran Canaria, el 11- } \\
11-2003 \text { a reserva de que se subsanen las defi- } \\
\text { ciencias advertidas por la Comisión de } \\
\text { Ordenación del Territorio y Medio Ambiente de } \\
\text { Canarias en sesión celebrada el } 20 \text { de mayo de } \\
2003 \text {, (B. O.C. núm. 234, lunes } 1 \text { de diciembre } \\
\text { de 2003). }\end{array}$ \\
\hline $\begin{array}{l}\text { Plan General de } \\
\text { Ordenación del } \\
\text { municipio de } \\
\text { Gáldar) }\end{array}$ & $\begin{array}{l}\text { Aprobación Defini- } \\
\text { tiva Parcial del Plan } \\
\text { el 20-07-2006 }\end{array}$ & $\begin{array}{l}\text { Se realizan de conformidad con lo establecido en } \\
\text { el artículo } 43.2 \text {, apdo., b) y c) del Texto Refun- } \\
\text { dido de las Leyes de Ordenación del Territorio de } \\
\text { Canarias y Espacios Naturales de Canarias, } \\
\text { aprobado por D.L. } 1 / 2000 \text {, de } 8 \text { de mayo. }\end{array}$ \\
\hline $\begin{array}{l}\text { El Plan General } \\
\text { de Ordenación de } \\
\text { Santa María de } \\
\text { Guía }\end{array}$ & $\begin{array}{l}\text { Aprobado definitiva- } \\
\text { mente por la COT- } \\
\text { MAC el } 28 \text { de julio } \\
\text { de } 2005\end{array}$ & $\begin{array}{l}\text { Dicho acuerdo fue publicado en el B.O.C. el } 18 \\
\text { de agosto de } 2005 \text {. }\end{array}$ \\
\hline $\begin{array}{l}\text { PIO_MP1 } \\
\text { Plan Territorial } \\
\text { Especial } \\
\text { Plan Insular de } \\
\text { Ordenación de } \\
\text { Gran Canaria } \\
\text { (PIOGC) Primera } \\
\text { modificación }\end{array}$ & $\begin{array}{l}\text { 27-11-2009. } \\
\text { Acuerdo Plenario. } \\
\text { Aprobación inicial }\end{array}$ & $\begin{array}{l}\text { Plan Insular de Ordenación de Gran Canaria. } \\
\text { Primera modificación. }\end{array}$ \\
\hline PTP-15 & $\begin{array}{l}\text { 16-11-2009. Con- } \\
\text { sejo de Gobierno. } \\
\text { Avance }\end{array}$ & $\begin{array}{l}\text { Plan Territorial Parcial: Ordenación del Litoral } \\
\text { del Norte: Arucas - Moya - Santa María de Guía. }\end{array}$ \\
\hline PTP-14 & $\begin{array}{l}\text { Aprobación Inicial } \\
\text { 17-05-2010. Con- } \\
\text { sejo de Gobierno. } \\
\text { Aprobación provi- } \\
\text { sional por el Ca- } \\
\text { bildo por } \\
\text { unanimidad el } \\
\text { 25-02-2011 }\end{array}$ & $\begin{array}{l}\text { Plan Territorial Parcial: Área de centralidad de } \\
\text { Gáldar y Santa María de Guía. }\end{array}$ \\
\hline PTE-37 & & $\begin{array}{l}\text { Plan Territorial Especial de Ordenación Turís- } \\
\text { tica de la Costa NW. }\end{array}$ \\
\hline
\end{tabular}

Fuente: elaboración propia a partir de la planificación existente de ámbito local. 


\section{Cuadro 4}

DESCRIPCIÓN DE LAS FASES DEL PLAN INSULAR DE GRAN CANARIA (PIOGC)

\begin{tabular}{|c|c|c|}
\hline Tipo & Número & Nombre \\
\hline Ley & $\begin{array}{l}\text { 1/1987, } \\
\text { de } 13 \text { de marzo }\end{array}$ & $\begin{array}{l}\text { Reguladora de los Planes Insulares de Ordenación. } \\
\text { 1. Da lugar a los Planes Insulares de Ordenación (P.I.O) de } \\
\text { las Islas consolidadas turísticamente. } \\
\text { 2. Introdujeron una importante novedad en la progra- } \\
\text { mación territorial de cada espacio insular a través del } \\
\text { concepto de «Techo Alojativo», vinculando, por tanto, a } \\
\text { los planes parciales (escala municipal). } \\
\text { 3. Esta situación provocó un predominio de las preten- } \\
\text { siones urbanizadoras-inmobiliarias caracterizadas, en su } \\
\text { mayoría) por ser individuales, anacrónicas y aisladas.... } \\
\text { Además es habitual que éstas omitan no sólo el interés } \\
\text { general, sino también las necesarias reflexiones de orden } \\
\text { económico, social y ambiental del contexto territorial en } \\
\text { el que se insertan (a escala municipal, insular y regional). } \\
\text { 4. Ello dio lugar a un espectro de derechos consolidados, in- } \\
\text { conexos, y extremadamente «blindados» materializados } \\
\text { o por materializar» }\end{array}$ \\
\hline Decreto & $\begin{array}{l}\text { 7/1995, de } 27 \text { de enero y } \\
42 / 1995, \text { de } 10 \text { de marzo }\end{array}$ & $\begin{array}{l}\text { Se aprueba definitivamente el Plan Insular de Ordenación } \\
\text { de Gran Canaria (PIOGC). }\end{array}$ \\
\hline Decreto & $55 / 2000$ de 10 de abril & $\begin{array}{l}\text { Establece el plazo para la adaptación del planeamiento mu- } \\
\text { nicipal de Gran Canaria al Plan Insular (PIOGC). }\end{array}$ \\
\hline Decreto & $\begin{array}{l}277 / 2003, \\
\text { de } 11 \text { de noviembre }\end{array}$ & $\begin{array}{l}\text { Plan Insular de Ordenación de Gran Canaria, Se aprueba } \\
\text { definitivamente el Plan Insular de Ordenación de Gran } \\
\text { Canaria, (PIOGC), el 11-11-2003 con la reserva de que se } \\
\text { subsanen las deficiencias advertidas por la Comisión de } \\
\text { Ordenación del Territorio y Medio Ambiente de Canarias } \\
\text { en sesión celebrada el } 20 \text { de mayo de 2003. (B. O.C. núm. } \\
\text { 234, lunes } 1 \text { de diciembre de 2003). }\end{array}$ \\
\hline Decreto & 64/2004 de 25 de mayo & $\begin{array}{l}\text { Por el que se subsanan las deficiencias no sustanciales del } \\
\text { (PIOGC). }\end{array}$ \\
\hline $\begin{array}{l}\text { Sentencia del TSJC } \\
\text { contra }\end{array}$ & $6-10-2008$ & $\begin{array}{l}\text { La sala } 2^{\text {a }} \text { de lo contencioso-Administrativo del TSJC dictó } \\
\text { sentencia contra las aprobaciones de los Decretos 277/2003, } \\
\text { de } 11 \text { de noviembre y 64/2004 de } 25 \text { de mayo (mirar infor- } \\
\text { mación más completa en la carpeta del PIOGC). }\end{array}$ \\
\hline $\begin{array}{l}\text { PIO_MP1. Plan Terri- } \\
\text { torial Especial. Plan } \\
\text { Insular de Ordenación } \\
\text { de Gran Canaria. (PI- } \\
\text { OGC) Primera modifi- } \\
\text { cación. }\end{array}$ & 27/11/2009 & $\begin{array}{l}\text { Plan Insular de Ordenación de Gran Canaria. (PIOGC) } \\
\text { Primera modificación. }\end{array}$ \\
\hline $\begin{array}{l}\text { (PIOGC) Primera } \\
\text { modificación. }\end{array}$ & $\begin{array}{l}\text { Acuerdo Plenario del Ca- } \\
\text { bildo de Gran Canaria. } \\
\text { Aprobación inicial }\end{array}$ & \\
\hline
\end{tabular}

Fuente: elaboración propia a partir del desarrollo del Plan Insular de Gran Canaria (PIOGC). 
BIBLIOGRAFÍA

Alcaraz Ramos, M. (dir.) (2007): El estado de derecho frente a la corrupción urbanística. Madrid, La Ley, 216 pp.

Arranz Lozano, M. (1990): El papel de la propiedad en el desarrollo espacial de Madrid: Sector NW (Distrito de Latina). Madrid, Editorial de la Universidad Complutense, $463 \mathrm{pp}$.

Burriel de Orueta, E. L. (2009): "Los límites del planeamiento urbanístico municipal, el ejemplo valenciano". Documents d'Anàlisi Geogràfica, 54, pp. 33-54.

Burriel de Orueta, E. L. (2008): "La década prodigiosa del urbanismo español (19972006)". Scripta Nova. Revista Electrónica de Geografía y Ciencias Sociales, XII/270.

Capel, H.(2002): La morfologia de las ciudades. I Sociedad, cultura y paisaje urbano. Barcelona, Ediciones del Serbal, Coleccción La Estrella Polar, 544 pp.

Gestión Urbanística de las Palmas, S.A. (1982): Normas Subsidiarias de Ordenación del Planeamiento del Municipio de Gáldar. Canarias, Gáldar.

Jerez Darias, L. M. (2004): "Planeamiento urbano y propiedad del suelo en una pequeña localidad: San Sebastián de La Gomera, Canarias, España". Biblio 3W. Revista Bibliográfica de Geografía y Ciencias Sociales de la Universidad de Barcelona, IX/ 527.

Jiménez Sánchez, F. (2008): "Boom urbanístico y corrupción política en España". Mediterráneo Económico, 14, pp. 263-285.

Hernández Luis, J. A. (2010): "Transformación de una gran propiedad agraria en suelo turístico: el ejemplo del Sur de Gran Canaria". Revista de Estudios de Turismo de Canarias y La Macaronesia, 2, pp. 23-36.

Lobo Rodrigo, A. (2010): "La adaptación de los Planes Generales de Ordenación al ordenamiento territorial de los recursos naturales y urbanístico canario", en M. R. Simancas Cruz (coord.): El impacto de la crisis en la economía canaria. Claves para el futuro, II. Tenerife, Real Sociedad Económica de Amigos del País de Tenerife, Tenerife, pp. 799-891.

Martín Fernández, C. S. (2011): "El proceso reciente de regulación de la vivienda ilegal en Canarias (1996-2009). B.A.G.E., 57, pp. 101-122.

Martín Fernández, C. S., Daranas Carballo, R. J. y García Cruz, I. (2011): "Coyuntura económica y cambio en los usos del suelo en la isla de La Palma (Canarias), el ejemplo del municipio de Tazacorte". Papeles de Geografía, 53/54, pp. 185-198.

Martín Martín V. O. y Jerez Darias, L. M. (2011): Normas Subsidiarias de Ordenación del Planeamiento del Municipio de Gáldar. Saarbrücken, Editorial Académica Española, $155 \mathrm{pp}$.

Martín Ruiz, J. F. (2005): La población de Canarias. Análisis sociodemográfico y territorial. Las Palmas de Gran Canaria, Anroart Ediciones, 421 pp.

Martín Ruiz, J. F. (1989): El Noroeste de Gran Canaria. Recursos hídricos, agricultura y población. Las Palmas de G. C., Ediciones del Cabildo de Gran Canaria, 204 pp.

Rodríguez Martín, J. A. (1978): "Algunas reflexiones teóricas sobre el proceso inmobiliario en Canarias”. Información Comercial Española, 543. 
Serrano Martínez, J. M. (2004): "Expansión del parque inmobiliario en España: algunas reflexiones desde la perspectiva territorial". Boletín económico de ICE, Información Comercial Española, 2798, pp. 11-30.

Simancas Cruz, M. R. (2010): "Moratoria turística y sostenibilidad territorial en destinos insulares consolidados. La experiencia de las Islas Canarias (2000-2010)", Proyecto de investigación. (No publicado).

Suay Rincón, J. y Domínguez Vila, A. (2010): Legislación urbanística, territorial y de medio ambiente de Canarias". Valencia, Editorial Tirant Lo Blanch, 1239 pp.

Tinaut Elorza, J. J. (2006): "Desarrollos recientes de la política estatal de vivienda en España: el Plan 2005-2008”. Revista Papeles de Economía, 109, pp. 273-290.

Torrent Navarro, L., Amador, M. a P. y Suarez Bosa, M. (1995): "Empresas extranjeras en Canarias: David J. Leacock". Disponible en: http://mdc.ulpgc.es/cdm4/ item_viewer.php?CISOROOT=/parabiblos $\&$ CISOPTR=39\&CISOBOX $=1 \&$ REC $=5$ (Fecha de consulta: 03/04/2012).

\section{RESUMEN}

En el artículo que se presenta a continuación damos a conocer las pautas del desarrollo urbano que han experimentado dos municipios de Gran Canaria, Gáldar y Guía, que, con Agaete conforman el sector noroeste de esa isla. La expansión urbana tuvo lugar fundamentalmente en la franja costera de ambos municipios, localizada por debajo de los $300 \mathrm{~m}$ de altitud sobre el nivel del mar, porque fue allí donde a comienzos del siglo xx se produjo un fuerte crecimiento demográfico, como resultado del desarrollo agrícola, en particular de los cultivos del plátano y de tomate; y porque a partir de los años sesenta, y más concretamente de los ochenta, los promotores inmobiliarios vieron que la transformación del suelo rural en urbano podía ser muy rentable. Este hecho originó una expansión urbana, en la franja espacial mencionada mediante la utilización de una norma legal como es el Convenio Urbanístico. Con ella se hacía abstracción de las Normas Subsidiarias de planificación y además se producía una gran connivencia de actuación entre los poderes locales y los promotores inmobiliarios. Todo ello con el fin de garantizar los intereses particulares de estos últimos, por delante del bien general de la comunidad, en estos municipios.

Palabras Clave: legislación urbanística; planificación; ordenación del territorio; Convenio Urbanístico; Gran Canaria; Islas Canarias; España.

\section{Abstract}

In the following article we will lay out the urban development guidelines which two municipalities of Gran Canaria have undergone, Gáldar and Guía which, together with Agaete, make up the Northwest sector of the island. The urban expansion took place mainly on the coastal strip of both municipalities, below 300m of altitude above sea level due to the strong demographic increase that took place there at the beginning of the $20^{\text {th }}$ century as a result of agricultural development, particularly in banana 
and tomato farming; and stemming from the fact that, from the sixties onwards, and more precisely the eighties, property developers realized that the transformation of rural land into urban could be very profitable. This fact caused an urban expansion in the aforementioned strip by means of the legal norm known as the Urban Development Agreement. With this agreement an abstraction was made of the Subsidiary Planning Regulations and furthermore a great connivance between local powers and property developers took place. All with the aim of warranting the private interests of the latter, over the general welfare of the community, in these municipalities.

KEY WORDS: urban planning legislation; planning; regional planning; Urban Development Agreement; Gran Canaria; Canary Islands; Spain.

\section{RÉSUMÉ}

Larticle que nous présentons ci de suite révèle quelles furent les normes qui favorisèrent le développement urbain de deux municipalités de la Grande Canarie : Gáldar et Guía, qui, avec Agaete, constituent le secteur Nord-Ouest de l'île. L'expansion urbaine eut lieu essentiellement le long de la frange côtière des deux villes, située à moins de 300 m d'altitude au-dessus du niveau de la mer. En effet, au début du xxe siècle, celles- ci avaient enregistré une forte croissance démographique due au développement de l'agriculture et, en particulier, des cultures de bananes et de tomates; d'autre part, à partir des années soixante, et surtout dans les années quatre-vingt, les promoteurs immobiliers virent que la transformation du sol rural en sol urbain pouvait être très rentable. Cela provoqua un étalement urbain le long de la bande littorale grâce à l'utilisation d'une norme légale : la Convention d'urbanisme. Celle-ci permettait d'ignorer les Normes Subsidiaires d'aménagement urbain, alors qu'une importante connivence d'action se produisait entre les pouvoirs locaux de ces deux municipalités et les promoteurs immobiliers, afin d'assurer les intérêts particuliers de ces derniers par-dessus l'intérêt général de la communauté.

MoTS CLÉS: législation urbanistique; planification urbaine; aménagement du territoire; Convention d'urbanisme; Grande Canarie; Îles Canaries; Espagne. 